\title{
The over-representation of binary DNA tracts in seven sequenced chromosomes
}

\section{Gad Yagil*}

Address: Dept. of Molecular Cell Biology, The Weizmann Institute of Biology, Rehovot, Israel 76100

Email: Gad Yagil* - gad.yagil@weizmann.ac.il

* Corresponding author

Published: 03 March 2004

BMC Genomics 2004, 5:19
Received: 18 October 2003

Accepted: 03 March 2004

This article is available from: http://www.biomedcentral.com/I47/-2/64/5/19

(C) 2004 Yagil; licensee BioMed Central Ltd. This is an Open Access article: verbatim copying and redistribution of this article are permitted in all media for any purpose, provided this notice is preserved along with the article's original URL.

\begin{abstract}
Background: DNA tracts composed of only two bases are possible in six combinations: $A+G$ (purines, R), C+T (pyrimidines, Y), G+T (Keto, K), A+C (Imino, M), A+T (Weak, W) and G+C (Strong, S). It is long known that all-pyrimidine tracts, complemented by all-purines tracts ("R.Y tracts"), are excessively present in analyzed DNA. We have previously shown that R.Y tracts are in vast excess in yeast promoters, and brought evidence for their role in gene regulation. Here we report the systematic mapping of all six binary combinations on the level of complete sequenced chromosomes, as well as in their different subregions.
\end{abstract}

Results: DNA tracts composed of the above binary base combinations have been mapped in seven sequenced chromosomes: Human chromosomes 21 and 22 (the major contigs); Drosophila melanogaster chr. 2R; Caenorhabditis elegans chr. I; Arabidopsis thaliana chr. II; Saccharomyces cerevisiae chr. IV and $M$. jannaschii. A huge over-representation, reaching million-folds, has been found for very long tracts of all binary motifs except $S$, in each of the seven organisms. Long R.Y tracts are the most excessive, except in D. melanogaster, where the K.M motif predominates. S (G, $C$ rich) tracts are in excess mainly in $C_{P} G$ islands; the $W$ motif predominates in bacteria. Many excessively long $W$ tracts are nevertheless found also in the archeon and in the eukaryotes. The survey of complete chromosomes enables us, for the first time, to map systematically the intergenic regions. In human and other chromosomes we find the highest over-representation of the binary DNA tracts in the intergenic regions. These over-representations are only partly explainable by the presence of interspersed elements.

Conclusions: The over-representation of long DNA tracts composed of five of the above motifs is the largest deviation from randomness so far established for DNA, and this in a wide range of eukaryotic and archeal chromosomes. A propensity for ready DNA unwinding is proposed as the functional role, explaining the evolutionary conservation of the huge excesses observed.

\section{Background}

In 1952, Erwin Chargaff published a paper in which he brought evidence that runs of pyrimidines are highly over- represented in eukaryotic DNA [1]. DNA was "depurinated" in formic acid and the remaining pyrimidines were subsequently size separated by the then novel technique 
of paper chromatography [2], see also [3]. An unexpectedly high number of pyrimidine and purine tracts ("isostichs"), 9 bases and higher, was found in human, calf, salmon and rye DNA $[4,5]$. These findings were subsequently corroborated by a number of techniques, incl. molecular hybridization rates [6-8]. The over-representation of long purine and pyrimidine runs could be exactly analyzed when sequences of many genes became available $[9,10]$. The phenomenon discovered by Chargaff turned out to be a very significant one - over-representation of the longer tracts reaches values of many ten-folds, as will be demonstrated on a genome-wide basis in this paper. Homopurine $(\mathrm{R})$ and homopyrimidine $(\mathrm{Y})$ tracts will be referred to jointly as "R.Y tracts", because whenever a run of pyrimidines is present on one strand, it is complemented by a run of purines on the opposite strand (the dot separates complementary strands, in accordance with IUBMB rules). It should be stressed that alternating A and $G$ (poly A-G) are only one component of R tracts, and any combination of A's and G's an make an R tract - see Additional file: 7 .

Examining increasing number of genes revealed that R.Y tracts are not the only over-represented binary DNA motif. Three additional combinations of two bases are possible [11], namely: A, T only ("W tracts"); G, C only ("S tracts"), and tracts which are $\mathrm{G}$, $\mathrm{T}$ on one strand complemented by A, C on the opposite strand (jointly: "K.M tracts"). The S tracts, found in high concentrations in certain regions, are well studied as CpG islands [12]. The abundance of these combinations was previously established in an assortment of mammalian genes [13] and in a yeast chromosome [14]. In bacteria, the $\mathrm{W}$ motif, rather than the R.Y motif, was found to be the predominating binary motif $[15,16]$.

In this paper, we shall map the occurrence of binary tracts in seven recently sequenced chromosomes, representing the major currently studied eukaryotic and archeal phyla (previous studies encompassed mainly incidentally selected gene regions). These chromosomes, especially the human and plant ones, also represent a large selection of intergenic regions not previously mapped. It will be shown that the huge over-representation is prevalent in all the selected chromosomes, in particular in their intronic and intergenic subregions. A functional significance of this remarkable departure of real DNA from random DNA has yet to be established. We have previously suggested, based on our experimental findings [17], that a DNA unwinding role, necessary for initiation of transcription, replication and other DNA directed processes, could be involved, as will be detailed in the Disscusion.

\section{Results}

\section{R.Y tracts in chromosome 22}

The chromosomes selected and their basic data are given in Table 1. Program TRACTS was applied to map the occurrence of binary DNA tracts in these chromosomes (See methods). The occurrence of R.Y tracts of different lengths in "contig 23", the main contig of human chromosome 22 (66.6\% of the chromosome) is shown in Table 2. In columns 2 and 3 of the table, the number of $\mathrm{R}$ and Y tracts of each length found in the GenBank-listed strand is listed. Opposite each Y tract there is of course an $\mathrm{R}$ tract, and vice versa. The number of $\mathrm{R}$ tracts of each length can be seen to be roughly equal to the number $\mathrm{Y}$ tracts. This justifies the joint consideration of the $\mathrm{R}$ and $\mathrm{Y}$ tracts as a pair (R.Y) at this stage.

Every tract length up to $78 \mathrm{nt}$ is represented, and many longer tracts are present. The longest tract found is a 367 nt long, an R tract (second column). In column 5, the number of R.Y tracts that are expected in random DNA of the same length and base composition as the analyzed contig is shown (see methods). It is seen that the number of tracts expected decreases much more rapidly than the number of tracts observed (column 4). In fact, for all tracts longer than $23 \mathrm{nt}$ not even a single tract is expected in randomized DNA (see column 5), while 644 such tracts are found at that length alone! (column 4). This enormous over-representation certainly calls for a biological explanation. The extent of over-representation is listed in column 9, which gives the ratio between the number of tracts (or bases) observed, to the number of tracts (or bases)

Table I

\begin{tabular}{|c|c|c|c|c|c|c|c|}
\hline & Chromosome & Date & Access. No. & Length & No. of genes b & $\begin{array}{l}\text { \%Exons + } \\
\text { Introns }\end{array}$ & Reference \\
\hline H. sapiens & 21 , contig "28" & $|7 / 4 / 0|$ & NT_0II5I2.3 & $28,515,322$ & 91 & 16 & {$[18]$} \\
\hline H. sapiens & 22, contig "23" & $|7 / 4 / 0|$ & NT_0I I620.5 & $22,998,450$ & 226 & 36 & [19] \\
\hline D. melanogaster & 2R (Right arm) & $7 / 11 / 02$ & NT_033778.I & $20,302,755$ & $2687^{c}$ & 57 & [20] \\
\hline C. elegans & I & $23 / 4 / 99$ & "chr_l" & $16,183,833^{a}$ & 2516 & 42.6 & {$[21]$} \\
\hline A. thaliana & II & $21 / 12 / 99$ & AE002093 & $19,647,09 \mid$ & 4116 & 41.7 & [22] \\
\hline S. cerevisiae & IV & $16 / 6 / 02$ & NC_00II 36.2 & $1,53 \mid, 929$ & 856 & 73.8 & [23] \\
\hline M. jannaschii & Main & $30 / 1 / 98$ & L77I7 & $1,664,970$ & 1715 & 87.1 & [24] \\
\hline
\end{tabular}

a I,44I,828 N bases excluded. bAs found by "ANEX" in the annotation file used. c Many alternatively spliced genes. 
Table 2: R.Y Tracts in Contig "23" of Chromosome 22 (22,998,450 nt)

\begin{tabular}{|c|c|c|c|c|c|c|c|c|c|}
\hline \multirow[b]{2}{*}{ Length } & \multicolumn{5}{|c|}{ No. of Tracts } & \multicolumn{2}{|c|}{ No of Bases } & \multicolumn{2}{|r|}{ Bases GE } \\
\hline & $R$ & $Y$ & Found(f) & Expected(e) & Difference & Found(f) & Expected(e) & f/e ratio & Ratio \\
\hline I & $2,275,282$ & $2,278,327$ & $4,553,609$ & $5,749,613$ & $-1,196,004$ & $4,553,609$ & $5,749,613$ & 0.79 & 1.00 \\
\hline 2 & $1,126,166$ & $1,125,235$ & $2,25 \mathrm{I}, 40 \mathrm{I}$ & $2,874,806$ & $-623,405$ & $4,502,802$ & $5,749,612$ & 0.78 & 1.07 \\
\hline 3 & 641,092 & 640,661 & $\mathrm{I}, 28 \mathrm{I}, 753$ & $1,437,403$ & $-155,650$ & $3,845,259$ & $4,312,209$ & 0.89 & 1.21 \\
\hline 4 & $4 \mid 3,142$ & 411,867 & 825,009 & 718,702 & 106,308 & $3,300,036$ & $2,874,806$ & 1.15 & 1.40 \\
\hline 5 & 214,646 & 214,404 & 429,050 & 359,351 & 69,699 & $2,145,250$ & I,796,754 & 1.19 & 1.58 \\
\hline 6 & 122,734 & 122,815 & 245,549 & 179,675 & 65,874 & $1,473,294$ & $1,078,052$ & 1.37 & 1.85 \\
\hline 7 & 68,181 & 68,317 & 136,498 & 89,838 & 46,660 & 955,486 & 628,864 & 1.52 & 2.21 \\
\hline 8 & 35,646 & 35,203 & 70,849 & 44,919 & 25,930 & 566,792 & 359,351 & 1.58 & 2.75 \\
\hline 9 & 21,592 & 21,485 & 43,077 & 22,459 & 20,618 & 387,693 & 202,135 & 1.92 & 3.69 \\
\hline 10 & 14,127 & 14,002 & 28,129 & 11,230 & 16,899 & 281,290 & II 2,297 & 2.50 & 5.13 \\
\hline 11 & 9,039 & 9,184 & 18,223 & 5614.9 & 12,608 & 200,453 & 61,763 & 3.25 & 7.32 \\
\hline 12 & 6,173 & 6,081 & 12,254 & 2807.4 & 9,447 & $\mid 47,048$ & 33,689 & 4.36 & 10.77 \\
\hline 13 & 4,139 & 4,118 & 8,257 & 1403.7 & 6,853 & $|07,34|$ & 18,248 & 5.88 & 16.27 \\
\hline 14 & 2,834 & 2,811 & 5,645 & 701.9 & 4,943 & 79,030 & $9,826.0$ & 8.04 & 25.27 \\
\hline 15 & 1,982 & 2,082 & 4,064 & 350.9 & 3,713 & 60,960 & $5,263.9$ & 11.58 & 40.35 \\
\hline 16 & 1,394 & 1,539 & 2,933 & 175.5 & 2,758 & 46,928 & $2,807.4$ & 16.72 & 65.73 \\
\hline 17 & $1,13 \mid$ & 1,093 & 2,224 & 87.7 & 2,136 & 37,808 & I,491.5 & 25.35 & 109.3 \\
\hline 18 & 913 & 932 & 1,845 & 43.9 & $|, 80|$ & 33,210 & 789.6 & 42.06 & 184.4 \\
\hline 19 & 710 & 695 & 1,405 & 21.9 & 1,383 & 26,695 & 416.7 & 64.06 & 312.5 \\
\hline 20 & 568 & 568 & 1,136 & 11.0 & 1,125 & 22,720 & 219.3 & 103.6 & 537.3 \\
\hline 21 & 480 & 478 & 958 & 5.5 & 953 & 20,118 & 115.2 & 174.7 & 931.5 \\
\hline 22 & 405 & 369 & 774 & 2.7 & 771 & 17,028 & 60.3 & 282.3 & 1,622 \\
\hline 23 & 305 & 339 & 644 & 1.4 & 643 & $|4,8| 2$ & 31.5 & 469.8 & 2,851 \\
\hline 24 & 302 & 292 & 594 & 0.7 & 593 & 14,256 & 16.5 & 866.6 & 5,041 \\
\hline 25 & 277 & 251 & 528 & 0.343 & 528 & 13,200 & 8.6 & 1,540 & 8,896 \\
\hline 26 & 220 & 222 & 442 & 0.171 & 442 & 11,492 & 4.5 & 2,579 & 15,706 \\
\hline 27 & 194 & 202 & 396 & 8.57E-02 & 396 & 10,692 & 2.3 & 4,622 & 27,896 \\
\hline 28 & 156 & 173 & 329 & $4.28 \mathrm{E}-02$ & 329 & 9,212 & 1.2 & 7,680 & 49,564 \\
\hline 29 & 121 & 162 & 283 & 2.14E-02 & 283 & 8,207 & 0.6 & 13,213 & 88,656 \\
\hline 30 & $12 \mid$ & $|4|$ & 262 & I.07E-02 & 262 & 7,860 & $3.21 \mathrm{E}-0 \mathrm{I}$ & 24,464 & 159,233 \\
\hline 31 & 89 & 117 & 206 & $5.35 \mathrm{E}-03$ & 206 & 6,386 & $1.66 \mathrm{E}-0 \mathrm{I}$ & 38,470 & 285,578 \\
\hline 32 & 92 & 78 & 170 & $2.68 \mathrm{E}-03$ & 170 & 5,440 & 8.57E-02 & 63,495 & 517,709 \\
\hline 33 & 83 & 80 & 163 & I.34E-03 & 163 & 5,379 & $4.42 \mathrm{E}-02$ & $|2|, 76 \mid$ & 945,205 \\
\hline 34 & 61 & 57 & 118 & 6.69E-04 & 118 & 4,012 & $2.28 \mathrm{E}-02$ & $|76,29|$ & I,72।,595 \\
\hline 35 & 60 & 57 & 117 & 3.35E-04 & 117 & 4,095 & $1.17 \mathrm{E}-02$ & 349,595 & $3,181,047$ \\
\hline 36 & 38 & 47 & 85 & I.67E-04 & 85 & 3,060 & $6.02 \mathrm{E}-03$ & 507,958 & $5,859,445$ \\
\hline 37 & 48 & 44 & 92 & 8.37E-05 & 92 & 3,404 & 3.10E-03 & $1.10 E+06$ & $1.09 \mathrm{E}+07$ \\
\hline 38 & 35 & 38 & 73 & 4. $18 \mathrm{E}-05$ & 73 & 2,774 & I.59E-03 & $1.74 \mathrm{E}+06$ & $2.03 E+07$ \\
\hline 39 & 43 & 47 & 90 & 2.09E-05 & 90 & 3,510 & $8.16 \mathrm{E}-04$ & $4.30 \mathrm{E}+06$ & $3.78 \mathrm{E}+07$ \\
\hline 40 & 30 & 27 & 57 & I.05E-05 & 57 & 2,280 & 4.18E-04 & $5.45 \mathrm{E}+06$ & $6.97 \mathrm{E}+07$ \\
\hline $31-40$ & 579 & 592 & $\mathrm{I},|7|^{\mathrm{a}}$ & $1.07 \mathrm{E}-02^{\mathrm{a}}$ & $1,|7|$ & $40,340^{a}$ & $3.42 \mathrm{E}-0 \mathrm{I}^{\mathrm{b}}$ & $5.45 \mathrm{E}+06$ & $6.97 \mathrm{E}+07^{b}$ \\
\hline $4 I-50$ & 161 & 168 & 329 & I.04E-05 & 329 & 14,669 & 4.39E-04 & $2.25 \mathrm{E}+09$ & $4.22 \mathrm{E}+10$ \\
\hline $51-60$ & 74 & 66 & 140 & $1.02 \mathrm{E}-08$ & 140 & 7,643 & 5.30E-07 & $6.02 E+11$ & $2.92 \mathrm{E}+13$ \\
\hline $61-70$ & 43 & 28 & 71 & $9.97 \mathrm{E}-12$ & 71 & 4,647 & $6.18 \mathrm{E}-10$ & $6.16 \mathrm{E}+14$ & $2.24 \mathrm{E}+16$ \\
\hline $71-80$ & 24 & 22 & 46 & $9.72 \mathrm{E}-15$ & 46 & 3,445 & $6.99 \mathrm{E}-13$ & $4.2 \mathrm{IE}+17$ & $1.78 \mathrm{E}+19$ \\
\hline $81-90$ & 21 & 21 & 42 & $9.51 \mathrm{E}-18$ & 42 & 3,603 & $7.79 \mathrm{E}-16$ & $4.3 \mathrm{IE}+20$ & $1.4 \mathrm{IE}+22$ \\
\hline $92-100$ & 14 & 14 & 28 & $4.63 \mathrm{E}-2 \mathrm{I}$ & 28 & 2,675 & $4.31 \mathrm{E}-19$ & $2.20 \mathrm{E}+23$ & $2.26 \mathrm{E}+25$ \\
\hline $101-110$ & 13 & 18 & 31 & $9.06 \mathrm{E}-24$ & 31 & 3,280 & $0.00^{c}$ & $0.00^{c}$ & $0.00^{c}$ \\
\hline $111-120$ & 3 & 7 & 10 & $8.24 \mathrm{E}-27$ & 10 & 1,142 & 0 & 0.00 & 0.00 \\
\hline $121-130$ & 7 & 5 & 12 & $8.56 \mathrm{E}-30$ & 12 & 1,509 & 0 & 0.00 & 0.00 \\
\hline$|3|-\mid 40$ & 3 & 10 & 13 & $5.92 \mathrm{E}-33$ & 13 & $\mathrm{I}, 746$ & 0 & 0.00 & 0.00 \\
\hline$|4|-\mid 50$ & 6 & 10 & 16 & $0.00^{c}$ & 16 & 2,319 & 0 & 0.00 & 0.00 \\
\hline$|5|-158$ & 3 & 2 & 5 & 0.00 & 5 & 774 & 0 & 0.00 & 0.00 \\
\hline $161-170$ & 0 & 6 & 6 & 0.00 & 6 & 999 & 0 & 0.00 & 0.00 \\
\hline$|7|-178$ & 5 & 3 & 8 & 0.00 & 8 & 1,398 & 0 & 0.00 & 0.00 \\
\hline$|8|-200$ & 3 & 6 & 9 & 0.00 & 9 & $|, 7| \mid$ & 0 & 0.00 & 0.00 \\
\hline $202-218$ & 6 & 2 & 8 & 0.00 & 8 & 1,666 & 0 & 0.00 & 0.00 \\
\hline
\end{tabular}


Table 2: R.Y Tracts in Contig "23" of Chromosome 22 (22,998,450 nt) (Continued)

\begin{tabular}{|c|c|c|c|c|c|c|c|c|c|}
\hline 224 & 0 & 2 & 2 & 0.00 & 2 & 448 & 0 & 0.00 & 0.00 \\
\hline 226 & 0 & I & I & 0.00 & I & 226 & 0 & 0.00 & 0.00 \\
\hline 229 & I & 0 & I & 0.00 & I & 229 & 0 & 0.00 & 0.00 \\
\hline 230 & 0 & I & I & 0.00 & I & 230 & 0 & 0.00 & 0.00 \\
\hline 237 & I & 0 & I & 0.00 & I & 237 & 0 & 0.00 & 0.00 \\
\hline $24 I$ & 0 & I & I & 0.00 & I & $24 I$ & 0 & 0.00 & 0.00 \\
\hline 250 & 0 & I & I & 0.00 & I & 250 & 0 & 0.00 & 0.00 \\
\hline 270 & 0 & I & 1 & 0.00 & I & 270 & 0 & 0.00 & 0.00 \\
\hline 308 & 0 & 2 & 2 & 0.00 & 2 & 616 & 0 & 0.00 & 0.00 \\
\hline 318 & 0 & I & I & 0.00 & I & 318 & 0 & 0.00 & 0.00 \\
\hline 325 & 0 & I & I & 0.00 & I & 325 & 0 & 0.00 & 0.00 \\
\hline 367 & I & 0 & I & 0.00 & I & 367 & 0 & 0.00 & 0.00 \\
\hline
\end{tabular}

a. Found and Expected for the range of lengths b. From here, the ratios are for the last in the range, e.g. for I = 40 in the $3 \mathrm{I}-40$ range. c. From here, values are not computable with single precision in our setup.

expected in random DNA. This ratio is below unity for the first three rows, namely for single pyrimidines (purines) flanked by two purines (pyrimidines), their doublets and triplets. The low ratio for the short tracts compensates for the over-representation of the longer tracts, which increases steadily up to enormous figures for the higher lengths (column 9). The increase in ratios is relatively smooth, as can also be seen in Fig. 1a, which indicates that a property special to a particular length or length group is not responsible for the high excesses found. We shall use the found/expected ratio values ("f/e ratios") as the main measure for the extent of binary tract over-representation in the coming Tables. In the last column, the f/e ratio is listed for all tracts longer or equal (also "Greater or Equal", or "GE") than the length given in the first column (calculated as GE bases found divided by GE bases expected, eq. (4)). The GE value is more meaningful for the longer tract lengths, when only few tracts are encountered, so that individual f/e ratios lose their significance.

\section{R.Y tracts in seven chromosomes}

Tables similar to Table 2 have been constructed for a series of other genomes as well as for the other binary DNA motifs. The Data for human chr. 21 and the Drosophila chromosome are shown in Figs. 1b and 1c as well as in the Additional files: 1 and 2, also at the authors web site http:/ /www.weizmann.ac.il/ lcyagil. The found/expected ratio values (f/e ratios) will be shown in most following tables, as the criterion for over-representation.

Table 3 gives the f/e ratios for R.Y tracts in seven chromosomes selected from sequenced genomes across the eukaryotic and archeal kingdoms. The major characteristics of the selected chromosomes have been listed in Table 1. In the last column of Table 3 a control run is shown five random $1 \mathrm{Mb}$ DNA sequences were generated and run by TRACTS, as an additional verification of the analytical formula used to calculate the expected values and f/e ratios (see methods). It can be seen that all the f/e ratios, except the longest, are close to unity. No R.Y tract longer than $21 \mathrm{nt}$ was found, as it should be. (a 24 nt K.M tract was found, see below). The standard deviations are less than $5 \%$ up to $13 \mathrm{nt}$ (Additional file: 4), when found tracts begin to be few. A larger SD is indeed expected for the longest tracts, because for example, for a $19 \mathrm{nt}$ tract, only 19 or 38 bases, or occasionally 57 bases, are possible for that length. The detailed data can be found in Additional file: 4 . The control runs thus confirm that tracts much longer than $21 \mathrm{nt}$ cannot be expected in randomly composed DNA.

The major conclusion from Table 3 is that the longer R.Y tracts are highly over-represented, up to extreme values, in all the seven genomes examined. In contrast, tracts of lengths up to three nt are under-represented in all the phyla studied, as already described for chromosome 22 . The longest tracts found in each species are roughly related to the length of the input DNA: From $50 \mathrm{nt}$ for the $1.65 \mathrm{Mb}$ M. jannaschii, to $55 \mathrm{nt}$ for yeast chromosome IV (the longest yeast chromosome), to 161 for the elegans chromosome (14.7 Mb); $194 \mathrm{nt}$ for the $20 \mathrm{Mb}$ of Arabidopsis, and up to $367 ; 568 \mathrm{nt}$ for the two human contigs. The one exception is the Drosophila half chromosome (20 Mb) where the longest tract is just $70 \mathrm{nt}$. It will be seen that the Drosophila chromosome is exceptional in other respects as well. A correlation between the size of the longest tract up to which every length is present, with the length of the input DNA sequence is also observed (Table 3): $31 \mathrm{nt}$ for jannaschii, 33 for yeast, $46 \mathrm{nt}$ for elegans, 50 for Arabidopsis, 78 and $98 \mathrm{nt}$ for the human contigs. Again, $39 \mathrm{nt}$ for Drosophila is an outlier. The lesser over-representation in Drosophila is also evident when individual numbers are compared to the other organisms; the highest excesses of long tracts are clearly in the two human contigs. The overall result is that the two human chromosomes exhibit the highest over-representation, with most other chromo- 

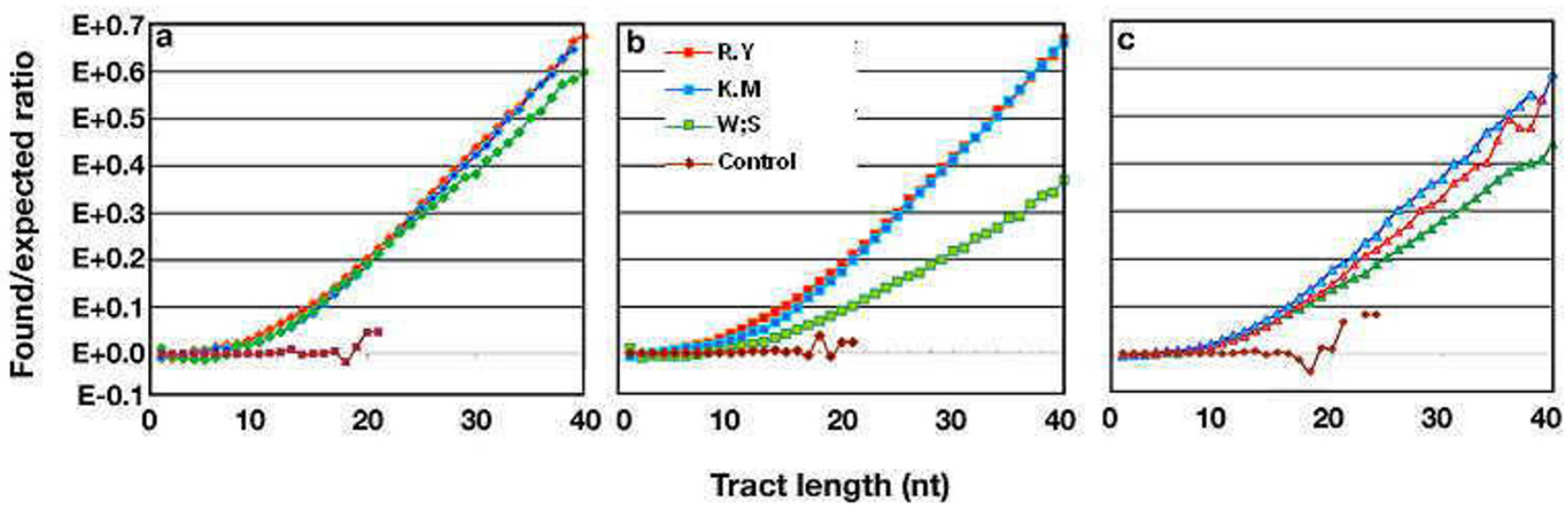

Tract length (nt)

\section{Figure I}

Binary tract over-representation in three chromosomes: The log ratios of found to expected number of binary tracts (f/e ratios) are plotted against tract length. Control runs are average values of five randomized DNA tracts of I Mb each, see Table 2, Additional Table 4 and text. a) Contig 23 of human chromosome 22, see Table I. b) Contig 28 of human chromosome 2I. c) Chromosome 2 of D. melanogaster, right arm. Tracts were plotted up to just $40 \mathrm{nt}$, to enhance resolution and to make visible the under-representation of very short tracts (f/e ratio below unity).

somes not far behind; the short M. jannaschii leads occasionally for 7-11 NT tracts. These conclusions can also be seen in Fig. 2a. Between the two human chromosomes, the gene poor chromosome 21 takes the lead.

\section{K.M tracts in seven chromosomes}

It was noted earlier that not only R.Y tracts are over-represented, but, at first a bit counter-intuitively, the other three binary DNA combinations as well. Thus, K.M tracts were found in large excess in the human $\beta$ globin complex and in organelle DNA [13], as well as in yeast chromosome 3 [14]. The data in Tables 4 and 5 show that these findings can be extended to the wider range of phyla studied here. In Table 4, the f/e ratios for K.M tracts are shown. As for the R.Y pair, the detailed outputs for each chromosome (see Additional files: 1, 2 and 3) show that roughly equal numbers of $\mathrm{K}$ tracts and $\mathrm{M}$ tracts are present in the analyzed strand, and justifies their joint consideration. Overall, it is clear that K.M tracts are also highly over-represented, in all seven chromosomes, even if to a lesser extent than the R.Y tracts. In humans, contig 23 of chromosome 22 shows the highest over-representations but beyond 67 nt many lengths are missing, the longest tract being just 91 nt long. In contig 28 many K.M lengths beyond 62 nt are missing; there are only two K.M tracts longer than $100 \mathrm{nt}$ (101 nt, $268 \mathrm{nt})$. The f/e ratios for K.M tracts are sometimes even higher than for R.Y tracts (in chr. 21 there are 9 cases between 32 and 51 nt and 5 cases in chr. 22). Beyond 52 nt, f/e ratios are always higher for R.Y than for K.M tracts.

The interesting genome is again Drosophila: Here the overrepresentation of K.M tracts is eventually 2-3 times higher than for the R.Y tracts (Fig. 1c) and is sometimes higher than in the human chromosomes (between 10-20 nt it is as high as in chr. 21 and not much lower at other lengths, Table 4). Whatever the function of the binary tracts may be, in Drosophila that function seems to be taken over, at least partly, by the K.M tracts. All K.M tract lengths are represented up to $45 \mathrm{nt}$, the longest K.M tract being just 74 nt. In Arabidopsis the K.M tracts are again in high excess, but to a lesser extent than the R.Y motif - there are only two tracts longer than $48 \mathrm{nt}$ (50 and $58 \mathrm{nt}$ ). The excess of K.M tracts in elegans and in yeast is less by an order of magnitude compared to humans (Fig. 2b; except for the yeast telomere), and is marginal but still significant in the archeon. Control runs with the same $5 \times 1 \mathrm{Mb}$ random sequences, but for the K.M motif, remain close to unity as expected (Table 4); the longest tract in this case is $24 \mathrm{nt}$ long, present in a single random $1 \mathrm{Mb}$ sequence.

\section{$W$ and $S$ tracts in the seven chromosomes}

$\mathrm{W}$ and $\mathrm{S}$ tracts are autocomplementary each, rather than complementing one another. $\mathrm{W}$ and $\mathrm{S}$ tracts are therefore separately compared. The f/e ratios for $\mathrm{W}$ tracts are shown in Table 5 and Fig. 2c. It is seen immediately that W tracts are also over-represented, but to a more variable degree 
A.

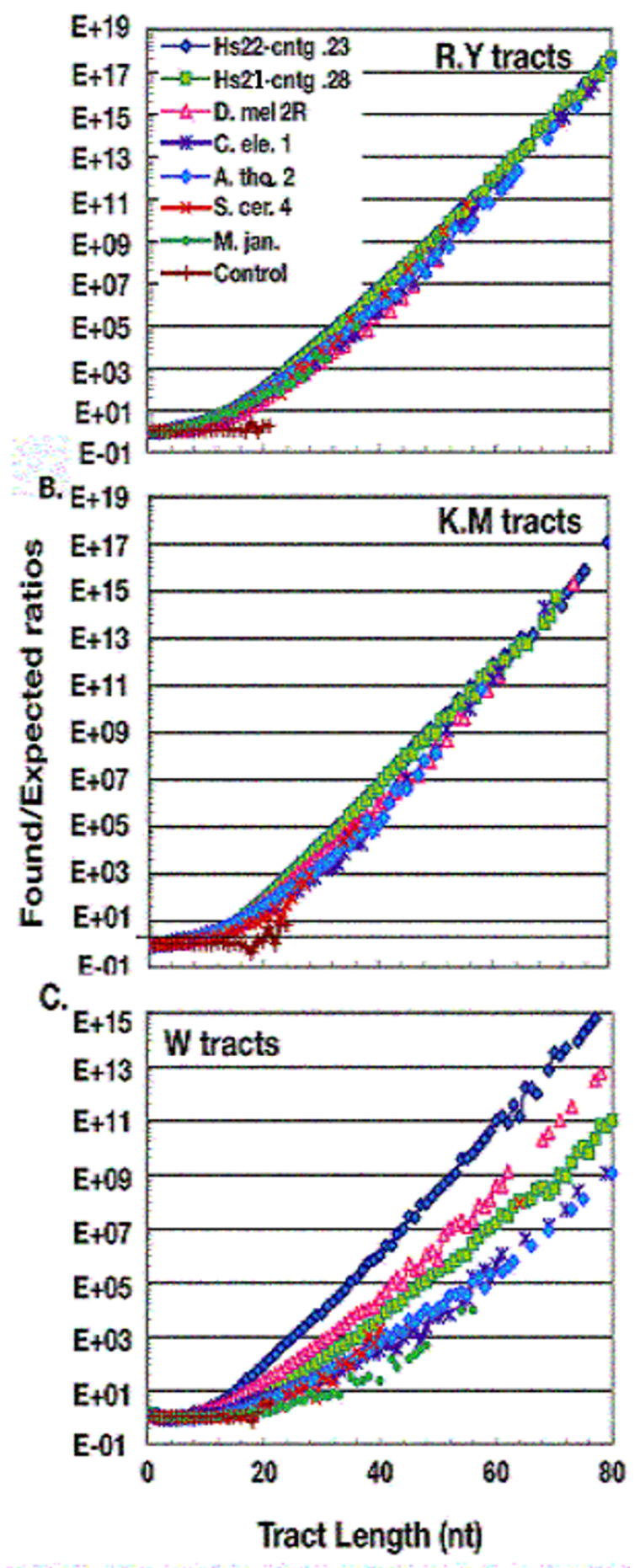

Figure 2

The over-representation of binary tracts in chromosomes of six organisms. The log ratios of found to expected number of binary tracts are plotted against tract length. Control runs are the same as in Fig. I. Tracts up to $80 \mathrm{nt}$ are plotted. The symbols for the seven chromosomes are given on the figure. A R.Y tracts. B K.M tracts. CW tracts than R.Y or K.M tracts. A difference of more than 100 fold is evident between the two human chromosomes for $\mathrm{W}$ tracts longer than $32 \mathrm{nt}$ : At that length, $\mathrm{f} / \mathrm{e}=18,990 \mathrm{in}$ contig 23 , vs. $\mathrm{f} / \mathrm{e}=227$ in contig 28 . This large difference is partly due to the sensitivity of the calculated value to the percentage of AT, which is $60.9 \%$ in contig 28 vs. $52.6 \%$ in contig 23 (\%AC and \%AG are always close to 50\%, "the second Chargaff parity rule", see end of discussion). A far higher number of $\mathrm{W}$ tracts are thus expected in chr. 21 by eq. (1), simply due to different $p$ and q values. In addition, the $60.9 \%$ AT of contig 28 is an average between a very gene poor half with a high \%AT ( $\sim 64 \%$ between coordinates $0-7 \mathrm{Mb}$, see Additional file: 8 ) and a gene richer half with $56 \%$ AT (towards the telomere of the chromosome). The actual f/e ratio in the gene rich domain is much closer to that of contig 23. In yeast, Arabidopsis and jannaschii (68.5 \%AT!), W tracts are under-represented up to $15 \mathrm{nt}$, but then are increasingly over-represented, reaching an excess of hundred-folds for 30-40 nt tracts. The $C$. elegans chromosome contains few very long $\mathrm{W}$ tracts, up to $96 \mathrm{nt}$. Again - the relatively low excess of $\mathrm{W}$ is partly due to the high percent AT. The actual number of tracts, not $\mathrm{f} / \mathrm{e}$ ratios, is closer to that of the R.Y or K.M motifs (Additional files: 1, 2 and 3). It should be added that the high \% AT can be explained only very partly by the mere presence of many long $\mathrm{W}$ tracts, because more than $89 \%$ of the A's and T's reside in the majority of short, underrepresented tracts, up to $10 \mathrm{nt}$; a certain compensation may be in place for strict quantitative comparison. Still, it can be concluded that the $\mathrm{W}$ motif in eukaryotes is also an extensively over-represented binary motif, in similarity to the situation in bacteria [15].

Finally, $\mathrm{S}$ tracts. There are many fewer long $\mathrm{S}$ tracts in all the chromosomes studied (data in Additional file: 5). S tracts are often concentrated near transcription start site, as part of the well studied CpG Islands $[12,25]$. Thus, in contig $23(47.4 \% \mathrm{G}, \mathrm{C})$ only five $\mathrm{S}$ tracts longer than $37 \mathrm{nt}$ are found ( 56 the longest). Nevertheless, in the $12-37 \mathrm{nt}$ range, over-representations increase from 1.12 up to 480,000 fold. In Arabidopsis (only 35.9\% G,C) the longest $\mathrm{S}$ tract is $20 \mathrm{nt}$, but over-representation still increases steadily up 200 fold, at length 20 . S tracts can thus be considered as another member of the over-represented class. Program TRACTS can be a convenient tool for detecting the CpG islands, espscially in its web version [26].

\section{Distribution in genic subregions}

In which genic subregions do the excessive tracts reside? Subprogram ANEX distributes the tracts between exon, intron and intercoding or intergenic classes. The term intergenic is appropriate when mRNA entries are parsed; in that case, UTR regions are evaluated as exons. The distribution between exons, introns and intergenic of all tracts $15 \mathrm{nt}$ and longer (GE 15) is shown in Table 6. W and 
Table 3: R.Y tracts in selected chromosomes. The numbers give for each length the number of found tracts divided by the number expected tracts, eq (I).

\begin{tabular}{|c|c|c|c|c|c|c|c|c|}
\hline & $\begin{array}{l}\text { H. sap. } 22 \\
\text { contig } 23\end{array}$ & $\begin{array}{l}\text { H. sap. } 21 \text {, } \\
\text { contig } 28\end{array}$ & D. mel. IIR & C. eleg. I & A. thal. II & S. cer. IV & M. jan. & Control \\
\hline Bases: & $22,998,450$ & $28,515,322$ & $20,302,755$ & $14,752,005$ & $|9,647.09|$ & $1,531,929$ & $1,664,970$ & $5 \times 1 \mathrm{Mb}$ \\
\hline \%A,G: & 50.0 & 50.1 & 50.0 & 50.0 & 49.9 & 50.1 & 50.3 & 50.0 \\
\hline \multicolumn{9}{|c|}{ Length(nt) } \\
\hline I & 0.79 & 0.86 & 0.96 & 0.78 & 0.86 & 0.89 & 0.78 & 1.00 \\
\hline 2 & 0.78 & 0.79 & 0.97 & 0.83 & 0.88 & 0.93 & 0.87 & 1.00 \\
\hline 3 & 0.89 & 0.88 & 0.98 & 0.88 & 0.91 & 0.87 & 0.79 & 1.00 \\
\hline 4 & 1.15 & 1.07 & 0.95 & 1.04 & 1.00 & 0.94 & 1.02 & 1.00 \\
\hline 5 & 1.19 & 1.20 & 1.06 & 1.31 & 1.12 & 1.13 & 1.27 & 1.00 \\
\hline 6 & 1.37 & 1.32 & 1.07 & 1.50 & 1.17 & 1.23 & 1.35 & 1.00 \\
\hline 7 & 1.52 & 1.46 & 1.07 & 1.56 & $1.4 \mathrm{I}$ & 1.36 & 1.87 & 1.00 \\
\hline 8 & 1.58 & 1.63 & 1.18 & 1.77 & 1.66 & 1.66 & 2.13 & 1.00 \\
\hline 9 & 1.92 & 2.04 & 1.27 & 2.16 & 1.92 & 1.86 & 2.04 & 1.01 \\
\hline 10 & 2.50 & 2.55 & 1.54 & 2.61 & 2.40 & 2.31 & 3.32 & 1.00 \\
\hline II & 3.25 & 3.21 & 1.84 & 3.03 & 3.12 & 2.91 & 3.94 & 1.04 \\
\hline 12 & 4.36 & 4.29 & 2.20 & 3.49 & 4.05 & 3.52 & 3.96 & 1.09 \\
\hline 13 & 5.88 & 5.54 & 2.89 & 4.20 & 5.34 & 4.81 & 6.66 & 1.09 \\
\hline 14 & 8.04 & 7.48 & 3.58 & 5.95 & 7.53 & 5.49 & 7.40 & 1.14 \\
\hline 15 & 11.58 & 10.16 & 4.83 & 7.73 & 10.36 & 8.89 & 7.30 & 1.05 \\
\hline 16 & 16.72 & 14.53 & 6.88 & 11.61 & 14.94 & 9.41 & 14.66 & 1.13 \\
\hline 17 & 25.35 & 21.48 & 9.93 & 16.54 & 23.05 & 14.02 & $17.7 \mid$ & 0.89 \\
\hline 18 & 42.06 & 33.01 & 14.38 & 25.45 & 28.84 & 18.81 & 22.87 & 2.31 \\
\hline 19 & 64.06 & 48.22 & 18.28 & 33.12 & 47.22 & 35.56 & 30.68 & 0.84 \\
\hline 20 & 103.6 & 72.85 & 27.99 & 52.46 & 80.36 & 41.02 & 52.55 & 1.68 \\
\hline 21 & 174.7 & 125.1 & 42.56 & 78.76 & 102.2 & 57.42 & 65.01 & 8.39 \\
\hline 22 & 282.3 & 199.9 & 71.06 & 98.38 & 175.9 & 98.42 & 94.94 & \\
\hline 23 & 469.8 & 335.7 & 110.7 & 217.2 & 251.0 & 54.67 & 69.90 & \\
\hline 24 & 866.6 & 575.0 & 150.4 & 270.7 & 384.1 & 131.2 & 159.6 & \\
\hline 25 & $|, 54|$ & 945.3 & 231.4 & 436.7 & 662.4 & 306.1 & 159.5 & \\
\hline 26 & 2,579 & 1,815 & 350.4 & 545.9 & 1,086 & 1,049 & 398.3 & \\
\hline 27 & 4,622 & 2,774 & 502.4 & 1,092 & 1,680 & 874.1 & 318.3 & \\
\hline 28 & 7,680 & 4,946 & 1,005 & 1,383 & 2,622 & 1,049 & 635.9 & \\
\hline 29 & 13,213 & 8,650 & 1,322 & $\mathrm{I}, 747$ & 4,971 & 2,796 & 3,811 & \\
\hline 30 & 24,464 & 14,667 & I,798 & 4,658 & 6,664 & 5,591 & 2,538 & \\
\hline 31 & 38,470 & 24,969 & 3,808 & 6,696 & 11,143 & 2,795 & 2,535 & \\
\hline 32 & 63,495 & 36,998 & 5,077 & 16,304 & 16,167 & 11,177 & - & \\
\hline 33 & $|2|, 76 \mid$ & 66,771 & 8,461 & 11,646 & 23,594 & 22,348 & - & \\
\hline 34 & $|76,29|$ & 145,557 & 10,153 & 18,633 & 38,448 & - & - & \\
\hline 35 & 349,595 & 204,479 & 30,460 & 32,608 & 108,348 & 178,697 & - & \\
\hline 36 & 507,958 & 380,048 & 81,226 & 37,266 & 209,697 & 89,326 & 80,562 & \\
\hline 37 & $1.10 \mathrm{E}+06$ & 711,906 & 54,150 & 186,332 & 209,687 & - & - & \\
\hline 38 & I.74E+06 & $1.50 \mathrm{E}+06$ & 54,150 & 372,665 & 391,396 & - & - & \\
\hline 39 & $4.30 \mathrm{E}+06$ & $2.12 E+06$ & 216,599 & 372,665 & 615,020 & - & - & \\
\hline 40 & $5.45 \mathrm{E}+06$ & $4.85 E+06$ & - & 447,198 & $1.12 E+06$ & - & - & \\
\hline 41 & I.IIE+07 & $7.38 \mathrm{E}+06$ & 433,193 & $1.79 E+06$ & $1.12 E+06$ & $2.85 \mathrm{E}+06$ & - & \\
\hline 42 & $1.87 E+07$ & $1.42 \mathrm{E}+07$ & 433,190 & $1.79 E+06$ & $2.24 \mathrm{E}+06$ & - & - & \\
\hline 43 & $3.44 \mathrm{E}+07$ & 2. $15 E+07$ & $2.60 \mathrm{E}+06$ & $2.39 E+06$ & $2.68 \mathrm{E}+06$ & - & - & \\
\hline 44 & $4.59 \mathrm{E}+07$ & $4.80 \mathrm{E}+07$ & $1.73 E+06$ & $4.77 E+06$ & $1.07 E+07$ & - & - & \\
\hline 45 & $7.96 \mathrm{E}+07$ & $8.12 E+07$ & - & $1.43 \mathrm{E}+07$ & $1.79 E+07$ & $4.56 \mathrm{E}+07$ & - & \\
\hline 46 & $1.29 E+08$ & $1.38 \mathrm{E}+08$ & $6.93 E+06$ & $9.54 \mathrm{E}+06$ & $4.29 \mathrm{E}+07$ & - & - & \\
\hline 47 & $3.30 \mathrm{E}+08$ & $2.75 E+08$ & - & - & $7.15 E+07$ & $1.82 E+08$ & $1.62 E+08$ & \\
\hline 48 & $6.6 \mathrm{IE}+08$ & $4.52 \mathrm{E}+08$ & - & $3.82 E+07$ & $2.86 \mathrm{E}+07$ & - & - & \\
\hline 49 & $1.13 \mathrm{E}+09$ & $7.08 \mathrm{E}+08$ & - & $2.29 \mathrm{E}+08$ & I.I $4 \mathrm{E}+08$ & - & - & \\
\hline 50 & $2.25 \mathrm{E}+09$ & $1.42 \mathrm{E}+09$ & I.IIE+08 & $1.53 E+08$ & $2.29 E+08$ & - & $1.29 E+09$ & \\
\hline 51 & $3.13 \mathrm{E}+09$ & $2.52 \mathrm{E}+09$ & - & 6.IIE+08 & - & $2.91 \mathrm{E}+09$ & - & \\
\hline 52 & $7.44 \mathrm{E}+09$ & $6.61 \mathrm{IE}+09$ & - & - & $4.58 \mathrm{E}+08$ & - & - & \\
\hline 53 & $1.64 \mathrm{E}+10$ & $1.07 E+10$ & - & - & $3.66 \mathrm{E}+09$ & - & - & \\
\hline 54 & $3.13 \mathrm{E}+10$ & $1.51 \mathrm{E}+10$ & - & $4.88 \mathrm{E}+09$ & - & - & - & \\
\hline 55 & $4.39 \mathrm{E}+10$ & $2.01 E+10$ & - & $4.88 \mathrm{E}+09$ & $3.66 \mathrm{E}+09$ & $4.65 \mathrm{E}+10$ & - & \\
\hline
\end{tabular}


Table 3: R.Y tracts in selected chromosomes. The numbers give for each length the number of found tracts divided by the number expected tracts, eq (I). (Continued)

\begin{tabular}{|c|c|c|c|c|c|}
\hline & & & & & \\
\hline 56 & I.07E+|| & $6.04 \mathrm{E}+10$ & - & $1.95 \mathrm{E}+10$ & $7.32 \mathrm{E}+09$ \\
\hline 57 & $|.38 \mathrm{E}+1|$ & $|.21 \mathrm{E}+1|$ & - & $5.86 \mathrm{E}+10$ & - \\
\hline 58 & $1.75 \mathrm{E}+1 \mathrm{I}$ & $|.8| E+||$ & - & - & $5.86 \mathrm{E}+10$ \\
\hline 59 & $4.51 E+11$ & $6.84 \mathrm{E}+1 \mathrm{I}$ & - & - & $5.86 \mathrm{E}+10$ \\
\hline 60 & $6.02 E+11$ & $8.85 E+11$ & - & - & - \\
\hline 61 & $1.20 \mathrm{E}+12$ & $1.77 E+12$ & - & $3.13 \mathrm{E}+11$ & $2.34 \mathrm{E}+\mathrm{II}$ \\
\hline 62 & $4.01 E+12$ & $3.22 \mathrm{E}+12$ & - & $6.25 \mathrm{E}+1 \mathrm{I}$ & $4.68 \mathrm{E}+1 \mathrm{I}$ \\
\hline 63 & $3.21 E+12$ & $7.72 E+12$ & - & - & $9.36 \mathrm{E}+11$ \\
\hline 64 & $1.12 E+13$ & $1.03 E+13$ & - & - & $1.87 E+12$ \\
\hline 65 & $2.89 E+13$ & $1.80 E+13$ & - & - & - \\
\hline 66 & $3.21 E+13$ & $3.08 \mathrm{E}+13$ & - & - & - \\
\hline 67 & $1.41 \mathrm{E}+14$ & $1.34 \mathrm{E}+14$ & - & - & - \\
\hline 68 & $2.05 E+14$ & $2.26 \mathrm{E}+14$ & - & - & - \\
\hline 69 & $2.57 \mathrm{E}+14$ & $2.88 \mathrm{E}+14$ & - & - & $5.99 \mathrm{E}+13$ \\
\hline 70 & $6.16 \mathrm{E}+14$ & $6.57 E+14$ & $4.65 E+14$ & - & $2.40 \mathrm{E}+14$ \\
\hline 71 & $1.23 E+15$ & $1.48 \mathrm{E}+15$ & & $6.40 \mathrm{E}+14$ & - \\
\hline 72 & $2.46 \mathrm{E}+15$ & $3.61 E+15$ & & $6.40 \mathrm{E}+14$ & - \\
\hline 73 & $4.93 \mathrm{E}+15$ & $5.91 E+15$ & & - & - \\
\hline 74 & $4.93 \mathrm{E}+15$ & $5.25 E+15$ & & - & $1.92 \mathrm{E}+15$ \\
\hline 75 & $1.97 E+16$ & $7.88 \mathrm{E}+15$ & & - & - \\
\hline 76 & $2.63 \mathrm{E}+16$ & $2.63 \mathrm{E}+16$ & & $1.02 \mathrm{E}+16$ & - \\
\hline 77 & $6.57 E+16$ & $5.25 \mathrm{E}+16$ & & $2.05 E+16$ & - \\
\hline 78 & $1.58 \mathrm{E}+17$ & $6.30 E+16$ & & - & - \\
\hline 79 & - & $2.52 \mathrm{E}+17$ & & - & - \\
\hline 80 & $4.21 \mathrm{E}+17$ & $4.20 \mathrm{E}+17$ & & - & $2.45 \mathrm{E}+17$ \\
\hline 81 & $6.31 \mathrm{IE}+17$ & $8.39 E+17$ & & - & $2.45 \mathrm{E}+17$ \\
\hline 82 & $2.52 \mathrm{E}+18$ & $1.68 \mathrm{E}+18$ & & - & - \\
\hline 83 & $8.41 E+17$ & $3.35 \mathrm{E}+18$ & & - & - \\
\hline 84 & $6.73 E+18$ & $2.68 \mathrm{E}+18$ & & - & $1.96 \mathrm{E}+18$ \\
\hline 85 & $1.35 E+19$ & $5.36 \mathrm{E}+18$ & & - & $7.84 \mathrm{E}+18$ \\
\hline 86 & $3.36 \mathrm{E}+19$ & $1.07 E+19$ & & $1.05 E+19$ & - \\
\hline 87 & 8.07E+19 & $5.36 \mathrm{E}+19$ & & - & - \\
\hline 88 & $1.08 \mathrm{E}+20$ & $1.29 \mathrm{E}+20$ & & $4.20 \mathrm{E}+19$ & - \\
\hline 89 & $2.69 \mathrm{E}+20$ & I.7IE+20 & & - & - \\
\hline 90 & $4.3 \mathrm{IE}+20$ & $4.29 \mathrm{E}+20$ & & - & - \\
\hline 91 & $1.29 E+2 \mid$ & $8.57 E+20$ & & - & - \\
\hline 92 & $|.72 E+2|$ & $6.85 E+20$ & & $0.00 \mathrm{E}+0 \mathrm{I}$ & - \\
\hline 93 & $4.3|E+2|$ & $2.06 E+2 I$ & & $0.00 \mathrm{E}+0 \mathrm{I}$ & - \\
\hline 94 & $6.89 E+21$ & 4. $|I E+2|$ & & - & - \\
\hline 95 & $6.89 \mathrm{E}+21$ & $2.74 \mathrm{E}+2 \mathrm{I}$ & & $0.00 \mathrm{E}+0 \mathrm{I}$ & - \\
\hline 96 & $1.38 \mathrm{E}+22$ & $5.48 \mathrm{E}+2 \mathrm{I}$ & & $0.00 \mathrm{E}+0 \mathrm{I}$ & $3.2 \mathrm{IE}+22$ \\
\hline 97 & 4.13E+22 & $5.47 E+22$ & & $0.00 E+01$ & $6.4 I E+22$ \\
\hline 98 & $2.76 \mathrm{E}+22$ & $1.09 \mathrm{E}+23$ & & & \\
\hline 99 & $2.76 \mathrm{E}+23$ & - & & & \\
\hline 100 & $2.20 \mathrm{E}+23$ & $3.50 \mathrm{E}+23$ & & & \\
\hline 101 & $0.00 \mathrm{E}+0 \mathrm{I}$ & $0.00 E+01$ & & & \\
\hline \multicolumn{6}{|c|}{$\begin{array}{l}\text { Beyond This point ratios are not calculable at our precision. } \\
\text { From here, number of tracts, or lengths, are shown }\end{array}$} \\
\hline 102 & I (IY) & - & & Also: & Also: \\
\hline 103 & $4(I Y+3 R)$ & - & & $114 \mathrm{nt}$ & $108 ; 110 \mathrm{nt}$ \\
\hline 104 & $2(I Y+I R)$ & $5(3 Y+2 R)$ & & $117 \mathrm{nt}$ & $111 ; 121 \mathrm{nt}$ \\
\hline 105 & $3(I Y+2 Y)$ & $2(2 Y)$ & & $120 \mathrm{nt}$ & $124 ; 139 \mathrm{nt}$ \\
\hline 106 & $5(2 Y+3 R)$ & $2(I Y+I R)$ & & $134 \mathrm{nt}$ & $145 ; 169 \mathrm{nt}$ \\
\hline 107 & $8(6 Y+2 R)$ & $3(2 Y+I R)$ & & $140 \mathrm{nt}$ & $174 ; 180 \mathrm{nt}$ \\
\hline 108 & I (IR) & $8(4 Y+4 R)$ & & $161 \mathrm{nt}$ & $182 ; 189 \mathrm{nt}$ \\
\hline 109 & $3(2 Y+I R)$ & I (IR) & & & $194 \mathrm{nt}$ \\
\hline 110 & $2(I Y+I R)$ & $6(4 Y+2 R)$ & & & \\
\hline
\end{tabular}

Longer tracts and Summary 
Table 3: R.Y tracts in selected chromosomes. The numbers give for each length the number of found tracts divided by the number expected tracts, eq (I). (Continued)

\begin{tabular}{|c|c|c|c|c|c|c|c|}
\hline & $\begin{array}{l}\text { H. sap. } 22 \\
\text { contig } 23\end{array}$ & $\begin{array}{c}\text { H. sap. } 21 \text {, } \\
\text { contig } 28\end{array}$ & D. mel. IIR & C. eleg. I & A. thal. II & S. cer. IV & M. jan. \\
\hline All found, up to (nt): & 78 & 98 & 39 & 46 & 50 & 33 & 31 \\
\hline Next missing (nt) & 114 & 102 & 45 & 52 & 54 & 37 & 37 \\
\hline 100 to $200 \mathrm{nt}$ (tracts): & 113 & 142 & - & 6 & 13 & - & - \\
\hline Longer than $200 \mathrm{nt}$ (tracts) & 22 & 24 & - & - & - & - & - \\
\hline Longest (nt): & 367 & 568 & 70 & 161 & 189 & 55 & 50 \\
\hline
\end{tabular}

A - (hyphen) means that no tract of that length is present

$S$ tracts are presented here as a pair, but since $S$ tracts are minority for tracts GE 15 , the f/e ratios represent practically the $\mathrm{W}$ tracts alone. Very high over-representations are again evident: Over-representations is highest for R.Y tracts in all genomes surveyed, except for Drosophila, where K.M tracts are in the largest excess.

The f/e ratios are lowest in coding regions (exons), with the exception of R.Y in M. jannaschii, (which is $87 \%$ coding, see column 7 of Table 1), and of W tracts in elegans. The lower excess in exons can be expected, since, for instance, an oligopurine on the coding strand imposes on the coded protein mostly polar amino acids (all-purine codons code for lys, arg, gln, also for gly).

Introns are the subregion in which K.M tracts are the most excessive, except for elegans, and jannaschii. In the fly introns have more excessive K.M tracts than R.Y tracts. The introns are the subregion richest in R.Y tracts in the fly, elegans and chr. 21 by the criterion used ( $\leq 15 \mathrm{nt})$. The wellknown oligopyrimidine close to the 3 ' splice site contributes to the excess of $Y$ tracts in introns. We also observe, in the full sequence outputs, many long binary tracts in the UTR regions, particularly in the 3' UTR. An example can be seen in reference [26]: The three R.Y tracts above position 19,000 of p53 listed there are in the 3' UTR of the gene. A suggested RNA stability signal of $9 \mathrm{~W}$ bases [27] may explain some of the $\mathrm{W}$ tracts, but many other long tracts, of all motifs, are found in the 3' UTR region, appearing often in blocks, and call for an explanation.

In the intergenic regions, R.Y tracts are the highest overrepresented subregion in human chr. 22, in Arabidopsis and in yeast, while in chr. 21, in fly and in worm, introns are the even somewhat richer in R.Y tracts. In the smaller, but gene rich $3.45 \mathrm{Mb}$ contig of chr. 21 (data not shown) R.Y tracts are highest in the intergenic regions, as in chr. 22. The excess of K.M over R.Y tracts in intergenic regions of Drosophila is to be particularly noted, while in the Arabidopsis chromosome their contribution is not very high.
A reviewer inquired how over-representation varies along a chromosome. The data in Additional file: 8 shows that for contig 28, f/e ratios for R.Y tracts decrease somewhat from the A,T rich, gene poor "desert" in the first half, to the gene rich second half. The $\mathrm{f} / \mathrm{e}$ ratio of the $\mathrm{W}$ tracts increase even stronger in the same direction, but that may be due to the fact, that expected values increase strongly with $\% \mathrm{~A}, \mathrm{~T}$ while actually found tracts increase much less if at all.

\section{Interspersed elements}

A major finding of the human sequencing project was that a very high portion of the human chromosomes consists of various interspersed elements introduced into the genome. To what extent can these elements be responsible for the over-represented binary tracts? For instance, most alu elements contain, at their end, 20-30 consecutive A's partly incorporated into the genome. To answer this question, several genes and chromosomal contigs were run by TRACTS after having been "masked" (interspersed elements taken out). This was done with program RepeatMasker, with parameter - nolow; this means that "simple" repeats and certain other low complexity tracts are not taken out; only LTR, MER, LINE and SINE elements were masked out (mainly alu runs, Additional file: 6). The longest sequence we could run was contig " 3.45 " of Chr. 21 , which is the q most contig of the chromosome, a relatively gene rich contig with $51.5 \%$ GC. After masking, $2,125,818$ bases out of the original 3,450,347 bases remained $(61 \%)$. The masked sequence was subjected to TRACTS. The results (Table 7 ) show that over-representation of all three binary pairs is reduced, but only to a limited extent - over-representation remains high for all three binary compositions. The most reduced motif is the $\mathrm{W}$ motif - possibly because of the last bases of the alu element. This means that a certain share of the long tracts does indeed reside in the inserted elements, but that many long tracts do reside in the non-masked fraction. This was true even when masking out also the "simple" and the "low complexity" elements. It is clear that over-represen- 
Table 4: K.M Tracts in selected chromosomes. Numbers are f/e ratios, i.e. number of tracts found at each length, divided by the number expected, eq.(I)

\begin{tabular}{|c|c|c|c|c|c|c|c|c|}
\hline & $\begin{array}{l}\text { H. sap } 22 \\
\text { contig } 23\end{array}$ & $\begin{array}{l}\text { H. sap } 21 \\
\text { contig } 28\end{array}$ & D. mel IIR & C. ele I & A. tha II & S. cer. IV & M. jan. & Control \\
\hline & $22,998,450$ & $28,515,322$ & $20,302,755$ & $14,752,005$ & $|9,647,09|$ & $1,531,929$ & $1,664,970$ & $5 \times I M b$ \\
\hline \%AC: & 0.501 & 0.502 & 0.500 & 0.500 & 0.499 & 0.500 & 0.500 & 0.500 \\
\hline \multicolumn{9}{|c|}{ Length } \\
\hline I & 0.82 & 0.84 & 0.88 & 0.83 & 0.93 & 0.90 & .95 & 1.00 \\
\hline 2 & 0.90 & 0.89 & 0.91 & 0.84 & 0.88 & 0.93 & .85 & 1.00 \\
\hline 3 & 0.97 & 0.98 & 0.97 & 0.90 & 0.88 & 0.96 & .99 & 1.00 \\
\hline 4 & 1.04 & 1.05 & 1.04 & 1.08 & 1.00 & 1.04 & 1.00 & 1.00 \\
\hline 5 & 1.12 & 1.14 & 1.11 & 1.24 & 1.11 & 1.12 & 1.11 & 1.01 \\
\hline 6 & 1.28 & 1.24 & 1.13 & 1.41 & 1.18 & 1.16 & 1.26 & 1.01 \\
\hline 7 & 1.30 & 1.31 & 1.21 & 1.52 & 1.36 & 1.28 & 1.39 & 1.01 \\
\hline 8 & 1.45 & 1.43 & $\mathrm{I} .40$ & 1.65 & 1.59 & 1.38 & 1.39 & 0.98 \\
\hline 9 & 1.54 & 1.57 & 1.55 & 1.88 & 1.86 & 1.43 & 1.39 & 1.00 \\
\hline 10 & 1.86 & 1.88 & 1.91 & 2.31 & 2.25 & 1.58 & 1.60 & 0.98 \\
\hline II & 2.29 & 2.22 & 2.33 & 2.70 & 2.81 & 1.78 & 1.79 & 1.00 \\
\hline 12 & 2.96 & 2.78 & 2.82 & 3.24 & 3.40 & 1.97 & 1.98 & 1.07 \\
\hline 13 & 3.67 & 3.15 & 3.73 & 3.76 & 4.34 & 2.12 & 2.14 & 1.12 \\
\hline 14 & 5.27 & 4.38 & 5.07 & 4.50 & 5.78 & 3.19 & 2.81 & 0.93 \\
\hline 15 & 7.23 & 5.97 & 6.80 & 5.66 & 7.80 & 3.04 & 3.15 & 1.03 \\
\hline 16 & 11.66 & 8.91 & 9.59 & 8.10 & 10.78 & 3.76 & 3.23 & 0.99 \\
\hline 17 & 18.29 & 14.78 & 14.68 & 10.00 & 14.80 & 6.67 & 3.15 & 0.72 \\
\hline 18 & 30.09 & 21.06 & 22.03 & 15.57 & 20.70 & 6.84 & 1.89 & 0.41 \\
\hline 19 & 46.13 & 33.74 & 32.59 & 19.05 & 26.41 & 7.53 & 2.52 & 1.29 \\
\hline 20 & 76.86 & 52.93 & 56.09 & 26.58 & 44.50 & 12.3 & 8.82 & 1.23 \\
\hline 21 & 130.6 & 91.90 & 79.53 & 36.96 & 60.19 & 13.7 & 2.52 & 4.50 \\
\hline 22 & 219.5 & 152.0 & 110.7 & 47.20 & 81.53 & 27.4 & 10.08 & - \\
\hline 23 & 395.3 & 267.6 & 214.0 & 87.57 & 142 & 11.0 & 10.08 & 6.50 \\
\hline 24 & 732.2 & 455.3 & 294.2 & 152.4 & 178 & 43.8 & - & 6.49 \\
\hline 25 & 1,237 & 802.4 & 585.0 & 168.3 & 290 & 87.6 & & \\
\hline 26 & 2,019 & 1,342 & 1,025 & 191.1 & 382 & 350.0 & & \\
\hline 27 & 3,232 & 2,532 & 1,467 & 345.7 & 669 & 350.0 & & \\
\hline 28 & 6,021 & 4,069 & 2,353 & 509.5 & 874 & 701.3 & & \\
\hline 29 & 10,034 & 7,274 & 3,596 & 655.1 & 993 & - & & \\
\hline 30 & 16,988 & 12,743 & 4,653 & $I, 60 \mid$ & 1,967 & - & & \\
\hline 31 & 26,694 & $22,|8|$ & 9,730 & 1,456 & 2,622 & - & & \\
\hline 32 & 50,773 & 37,754 & 11,845 & $\mathrm{I}, 747$ & 3,933 & - & & \\
\hline 33 & 100,049 & 62,900 & 21,151 & 2,329 & 6,991 & - & & \\
\hline 34 & 150,816 & 105,392 & 43,994 & 6,987 & 13,982 & $2.24 E+04$ & & \\
\hline 35 & 316,553 & 227,460 & 60,914 & 27,950 & 13,982 & $4.49 \mathrm{E}+04$ & & \\
\hline 36 & 513,634 & 402,082 & 108,290 & 18,633 & 34,953 & $8.97 E+04$ & & \\
\hline 37 & 848,064 & 775,120 & 162,433 & 18,633 & 41,942 & - & & \\
\hline 38 & $1.86 E+06$ & $1.26 \mathrm{E}+06$ & 270,718 & 111,800 & $|67,76|$ & - & & \\
\hline 39 & $2.87 E+06$ & $2.52 E+06$ & 216,572 & 74,533 & 55,918 & - & & \\
\hline 40 & $5.64 \mathrm{E}+06$ & $3.82 \mathrm{E}+06$ & 757,990 & - & ||$|, 83|$ & - & & \\
\hline 41 & $9.17 E+06$ & $8.86 \mathrm{E}+06$ & $1.08 \mathrm{E}+06$ & - & $223,65 I$ & $2.87 E+06$ & & \\
\hline 42 & $1.76 E+07$ & $1.59 E+07$ & $1.30 \mathrm{E}+06$ & - & 894,562 & - & & \\
\hline 43 & $3.59 \mathrm{E}+07$ & $2.50 \mathrm{E}+07$ & $2.60 \mathrm{E}+06$ & - & $3.58 \mathrm{E}+06$ & - & & \\
\hline 44 & $3.97 \mathrm{E}+07$ & $4.76 \mathrm{E}+07$ & $8.66 \mathrm{E}+06$ & - & $3.58 \mathrm{E}+06$ & - & & \\
\hline 45 & $7.03 E+07$ & $1.00 \mathrm{E}+08$ & $1.04 \mathrm{E}+07$ & $9.54 \mathrm{E}+06$ & $3.58 \mathrm{E}+06$ & Also: & & \\
\hline 46 & 2.14E+08 & $1.07 E+08$ & - & - & - & $97 n t$ & & \\
\hline 47 & $3.67 \mathrm{E}+08$ & $3.02 \mathrm{E}+08$ & $1.39 \mathrm{E}+07$ & - & $1.43 E+07$ & $2.07 E+23$ & & \\
\hline 48 & $6.85 \mathrm{E}+08$ & $4.09 E+08$ & $5.54 \mathrm{E}+07$ & - & $5.72 E+07$ & & & \\
\hline 49 & $1.27 E+09$ & $8.18 E+08$ & $5.54 \mathrm{E}+07$ & - & - & $155 \mathrm{nt}$ & & \\
\hline 50 & $9.78 \mathrm{E}+08$ & $7.79 E+08$ & $2.22 \mathrm{E}+08$ & $1.53 E+08$ & I. $14 \mathrm{E}+08$ & (telomere) & & \\
\hline 51 & $3.52 \mathrm{E}+09$ & 3.IIE+09 & - & - & - & & & \\
\hline 52 & $5.87 \mathrm{E}+09$ & $3.42 \mathrm{E}+09$ & $4.43 E+08$ & $1.22 \mathrm{E}+09$ & - & & & \\
\hline 53 & $7.82 E+09$ & $4.35 E+09$ & - & - & - & & & \\
\hline 54 & 2. $19 \mathrm{E}+10$ & $1.37 \mathrm{E}+10$ & $3.55 \mathrm{E}+09$ & - & - & & & \\
\hline 55 & $1.25 \mathrm{E}+10$ & $1.74 \mathrm{E}+10$ & $3.55 \mathrm{E}+09$ & - & - & & & \\
\hline
\end{tabular}


Table 4: K.M Tracts in selected chromosomes. Numbers are f/e ratios, i.e. number of tracts found at each length, divided by the number expected, eq.(I) (Continued)

\begin{tabular}{llllll}
\hline 56 & $7.51 \mathrm{E}+10$ & $4.47 \mathrm{E}+10$ & - & $9.77 \mathrm{E}+09$ & - \\
57 & $7.51 \mathrm{E}+10$ & $2.98 \mathrm{E}+10$ & - & - & $5.86 \mathrm{E}+10$ \\
58 & $1.50 \mathrm{E}+11$ & $1.79 \mathrm{E}+11$ & - & - & \\
59 & $2.50 \mathrm{E}+11$ & $2.38 \mathrm{E}+11$ & $5.68 \mathrm{E}+10$ & - & $1.56 \mathrm{E}+11$ \\
60 & $7.01 \mathrm{E}+11$ & $4.75 \mathrm{E}+11$ & - & - & \\
61 & $6.00 \mathrm{E}+11$ & $3.17 \mathrm{E}+11$ & $2.27 \mathrm{E}+11$ & $3.13 \mathrm{E}+11$ & \\
62 & $1.60 \mathrm{E}+12$ & $9.50 \mathrm{E}+11$ & - & - \\
63 & $1.60 \mathrm{E}+12$ & - & - & - \\
64 & $3.20 \mathrm{E}+12$ & $2.53 \mathrm{E}+12$ & - & - \\
65 & $9.61 \mathrm{E}+12$ & $5.05 \mathrm{E}+12$ & - & - \\
66 & $6.40 \mathrm{E}+12$ & $5.05 \mathrm{E}+12$ & - & - \\
67 & $1.28 \mathrm{E}+13$ & - & - & - \\
68 & - & - & - & $1.60 \mathrm{E}+14$ \\
69 & $5.12 \mathrm{E}+13$ & $4.03 \mathrm{E}+13$ & - & - \\
70 & - & $8.05 \mathrm{E}+13$ & - & - \\
71 & - & $4.83 \mathrm{E}+14$ & - & - \\
72 & $2.05 \mathrm{E}+14$ & - & - & - \\
73 & $1.89 \mathrm{E}+14$ & - & - & \\
74 & $1.64 \mathrm{E}+15$ & - & $1.86 \mathrm{E}+15$ & - \\
75 & $3.28 \mathrm{E}+15$ & - & & \\
76 & $6.55 \mathrm{E}+15$ & - & & \\
80 & $1.05 \mathrm{E}+17$ & - & & \\
91 & $2.14 \mathrm{E}+20$ & - & & \\
93 & - & $6.61 \mathrm{E}+20$ & & \\
Also Found (nt) & - & 101,268 & & \\
\hline
\end{tabular}

\section{Summary}

\begin{tabular}{lccccccc}
\hline & H. sap. 22, & H. sap. 2I, & D. mel. IIR & C. eleg. I & A. thal. II & S. cer. IV & M. jan. \\
contig 23 & contig 28 & & 45 & 39 & 45 & 28 & 23 \\
All found, up to (nt): & 67 & 62 & 67 & 51 & 41 & 49 & 30 \\
Next missing (nt) & 70 & 268 & 74 & 69 & 58 & 155 & 23 \\
Longest (nt): & 91 & & & &
\end{tabular}

tation cannot be explained as stemming mainly from so far identified inserted elements.

\section{Discussion}

The main finding reported here is that DNA tracts consisting of only two of the bases are in vast excess all over the animal and plant kingdoms, reaching mega-fold values. The highest excesses are found for R.Y tracts in humans and in other mammals, as observed originally in the pioneering work of Erwin Chargaff and coworkers [29]. In certain organisms - like in Drosophila - K.M tracts prevail. In bacteria, $\mathrm{W}$ tracts are the most over-represented binary motif [15], a finding also anticipated by Chargaff and coworkers [29]. One caveat - only one chromosome or contig, from a single species in a particular phylum, is discussed here, except for the two human contigs. Two yeast chromosomes and one Drosophila segment were previously reported, and all show similar abundances $[14,30]$.

Gentles and Karlin [31] report a distinct dinucleotide signature for each of the genomes studied here. The four dinuleotides present in homopurine tracts are $A A, G G$,
GA, and AG. These four dinucleotides are indeed over-represented in the genomes surveyed by Gentles and Karlin (except in Drosophila!). The rarity of CpG dinucleotides most probably contributes to the low number of $S$ tracts in humans. On the other hand, only a minor percentage of all bases (and dinucleotides) resides in long tracts: For instance, only $5.5 \%$ of all bases in contig 23 of chr. 22 are in binary tracts longer than $10 \mathrm{nt}$ (Table 2). Long tracts are thus not necessarily the major factor determining the dinucleotide signature. It is worth to note that the D. melanogaster chromosome, besides the high K.M ratios, manifests also the highest excess of long $\mathrm{W}$ tracts (Table 5), along with $E$. coli and $H$. influenzae; a closer relationship between these organisms has also been noted when dinucleotide signatures of E. coli and Drosophila were compared [31].

A comment on the equations used to calculate expected values (eqs. 1-4): It was assumed tacitly that compositional frequencies are neighbor independent (zero Markov order). Lower tract abundances would have been obtained, if higher order dependencies were introduced. 
Table 5: W Tracts in Selected Chromosomes. The numbers give for each length the number of found tracts divided by the number expected tracts, eq ( 1 ).

\begin{tabular}{|c|c|c|c|c|c|c|c|c|}
\hline & $\begin{array}{l}\text { H. sap. } 22 \\
\text { contig } 23\end{array}$ & $\begin{array}{l}\text { H. sap. } 21 \text {, } \\
\text { contig } 28\end{array}$ & D. mel. IIR & C. eleg. I & A. thal. II & S. cer. IV & M. jan. & Control \\
\hline Bases & $22,998,450$ & $28,515,322$ & $20,302,755$ & $14,752,005$ & $|9,647,09|$ & I,53।,929 & $1,664,970$ & $5 \times 1 \mathrm{Mb}$ \\
\hline \%AT: & 52.6 & 60.9 & 56.0 & 64.0 & 64.1 & 62.1 & 68.6 & \\
\hline I & 1.27 & 1.24 & 1.00 & 1.04 & 1.06 & 0.98 & 0.99 & 1.00 \\
\hline 2 & 0.89 & 0.95 & 0.87 & 0.97 & 1.13 & 1.11 & 0.98 & 1.00 \\
\hline 3 & 0.78 & 0.87 & 0.85 & 0.80 & 1.03 & 0.98 & 0.92 & 1.00 \\
\hline 4 & 0.76 & 0.84 & 0.93 & 0.86 & 0.98 & 1.00 & 0.88 & 1.00 \\
\hline 5 & 0.75 & 0.84 & 0.97 & 0.95 & 0.91 & 1.01 & 1.06 & 1.00 \\
\hline 6 & 0.82 & 0.85 & 0.95 & 1.00 & 0.82 & 0.91 & 0.92 & 1.00 \\
\hline 7 & 0.95 & 0.90 & 1.04 & 1.07 & 0.81 & 0.92 & 1.02 & 0.99 \\
\hline 8 & 1.49 & 1.05 & 1.25 & 1.06 & 0.82 & 0.97 & 1.14 & 0.98 \\
\hline 9 & 1.50 & 1.10 & 1.46 & 1.13 & 0.85 & 0.93 & 0.99 & 0.99 \\
\hline 10 & 1.75 & 1.19 & 1.78 & 1.19 & 0.90 & 0.95 & 1.03 & 0.98 \\
\hline 11 & 2.38 & 1.41 & 2.10 & 1.21 & 0.95 & 0.94 & 1.08 & 1.02 \\
\hline 12 & 2.89 & 1.55 & 2.47 & 1.26 & 1.04 & 0.89 & 0.96 & 1.06 \\
\hline 13 & 4.04 & 1.72 & 3.04 & 1.38 & 1.12 & 0.91 & 1.15 & 1.24 \\
\hline 14 & 5.73 & 2.08 & 3.78 & 1.63 & 1.28 & 0.93 & 1.28 & 0.94 \\
\hline 15 & 8.33 & 2.53 & 5.00 & 1.88 & 1.45 & 1.13 & 1.19 & 0.99 \\
\hline 16 & 13.59 & 3.12 & 6.73 & 2.42 & 1.67 & 1.14 & 1.32 & 1.01 \\
\hline 17 & 23.49 & 3.94 & 8.68 & 2.94 & 2.04 & 1.21 & 1.33 & 1.12 \\
\hline 18 & 32.84 & 4.78 & 11.33 & 3.40 & 2.42 & 1.38 & $1.4 \mathrm{I}$ & 0.66 \\
\hline 19 & 50.82 & 6.11 & 15.47 & 4.19 & 2.96 & 1.75 & 1.59 & 1.36 \\
\hline 20 & 79.24 & 7.96 & 22.23 & 4.96 & 3.73 & 2.63 & 1.36 & 2.82 \\
\hline 21 & 132.7 & 9.92 & 28.73 & 5.25 & 4.50 & 2.72 & 1.49 & 2.86 \\
\hline 22 & 214.1 & 13.57 & 38.57 & 6.83 & 4.91 & 2.27 & 1.81 & 1.00 \\
\hline 23 & 362.3 & 18.37 & 46.58 & 6.92 & 6.69 & 2.35 & 2.60 & \\
\hline 24 & 542.3 & 24.43 & 73.95 & 8.99 & 8.74 & 6.31 & 2.19 & \\
\hline 25 & 882.6 & 33.06 & 103.4 & 12.26 & 10.39 & 6.78 & 3.41 & \\
\hline 26 & 1,355 & 42.51 & 150.1 & 12.39 & 12.68 & 9.83 & 3.87 & \\
\hline 27 & 2,061 & 50.14 & 205.0 & 14.55 & 18.18 & $|2.3|$ & 4.03 & \\
\hline 28 & 3,323 & 74.65 & 293.6 & 16.50 & 18.70 & 8.49 & 7.29 & \\
\hline 29 & 5,538 & 94.83 & 416.8 & 24.25 & 26.51 & 4.56 & 5.15 & \\
\hline 30 & 6,465 & 145.7 & 618.8 & 28.41 & 36.50 & 29.37 & 6.00 & \\
\hline 31 & $|2,62|$ & 171.0 & 860.5 & 41.73 & 46.36 & 23.65 & 5.84 & \\
\hline 32 & 18,990 & 277.2 & 1,217 & 31.35 & 64.04 & 19.05 & 7.45 & \\
\hline 33 & 29,963 & 342.3 & 1,845 & 55.41 & 90.69 & 92.02 & 6.21 & \\
\hline 34 & 49,956 & 459.7 & 2,786 & 68.44 & 104.3 & 98.80 & - & \\
\hline 35 & $|0|, 53 \mid$ & 723.0 & 4,446 & 88.03 & 118.0 & 79.56 & 29.70 & \\
\hline 36 & 138,383 & 805.0 & 6,586 & 103.1 & 173.6 & 256.3 & 19.25 & \\
\hline 37 & 270,878 & 1,452 & 8,640 & 161.1 & 200.2 & 206.3 & 21.05 & \\
\hline 38 & 522,205 & 2,172 & 9,963 & 287.6 & 253.1 & 996.9 & 30.70 & \\
\hline 39 & 661,419 & 2,574 & 11,744 & 224.6 & 539.3 & 535.2 & - & \\
\hline 40 & 956,122 & 4,805 & 24,918 & 292.3 & 533.2 & $\mathrm{I}, 724$ & 21.76 & \\
\hline 41 & $2.23 E+06$ & 7,104 & 44,059 & 502.2 & 1,087 & - & - & \\
\hline 42 & $2.27 E+06$ & 11,670 & 84,394 & 499.2 & 797.6 & - & 138.84 & \\
\hline 43 & $5.62 \mathrm{E}+06$ & 12,780 & $|49,22|$ & 334.2 & I,554 & - & 67.49 & \\
\hline 44 & $9.25 \mathrm{E}+06$ & 20,295 & 81,183 & 869.9 & 1,454 & - & - & \\
\hline 45 & $2.64 \mathrm{E}+07$ & 40,237 & 466,518 & 1,359 & 3,778 & - & 143.52 & \\
\hline 46 & $2.44 \mathrm{E}+07$ & 49,102 & 253,807 & 1,698 & 2,945 & - & 209.29 & \\
\hline 47 & $7.32 \mathrm{E}+07$ & 80,662 & 336,576 & 663 & 5,510 & - & 305.21 & \\
\hline 48 & $7.88 \mathrm{E}+07$ & 101,928 & 991,860 & $2,07 \mid$ & 10,022 & - & 445.08 & \\
\hline 49 & $1.4 I E+08$ & 167,440 & $1.40 \mathrm{E}+06$ & 6,470 & 6,696 & - & - & \\
\hline 50 & $2.5 \mathrm{IE}+08$ & 247,554 & $6.20 \mathrm{E}+05$ & 5,053 & 10,440 & - & - & \\
\hline 51 & 4. $13 \mathrm{E}+08$ & 338,889 & $5.48 \mathrm{E}+06$ & 7,893 & 13,563 & - & - & \\
\hline 52 & $6.04 \mathrm{E}+08$ & 371,137 & $9.69 \mathrm{E}+06$ & 6,164 & 29,605 & - & - & \\
\hline 53 & $1.03 E+09$ & 609,680 & $1.37 E+07$ & - & 32,968 & - & - & \\
\hline 54 & $3.49 \mathrm{E}+09$ & 901,390 & $1.82 \mathrm{E}+07$ & 15,038 & 41,119 & - & 8560.91 & \\
\hline 55 & $3.73 \mathrm{E}+09$ & 987,165 & $1.07 E+07$ & 23,489 & 32,053 & - & - & \\
\hline 56 & $5.5 \mathrm{IE}+09$ & $2.43 \mathrm{E}+06$ & $1.90 \mathrm{E}+07$ & $\mid 46,758$ & 99,945 & - & 9102.78 & \\
\hline
\end{tabular}


Table 5: W Tracts in Selected Chromosomes. The numbers give for each length the number of found tracts divided by the number expected tracts, eq (I). (Continued)

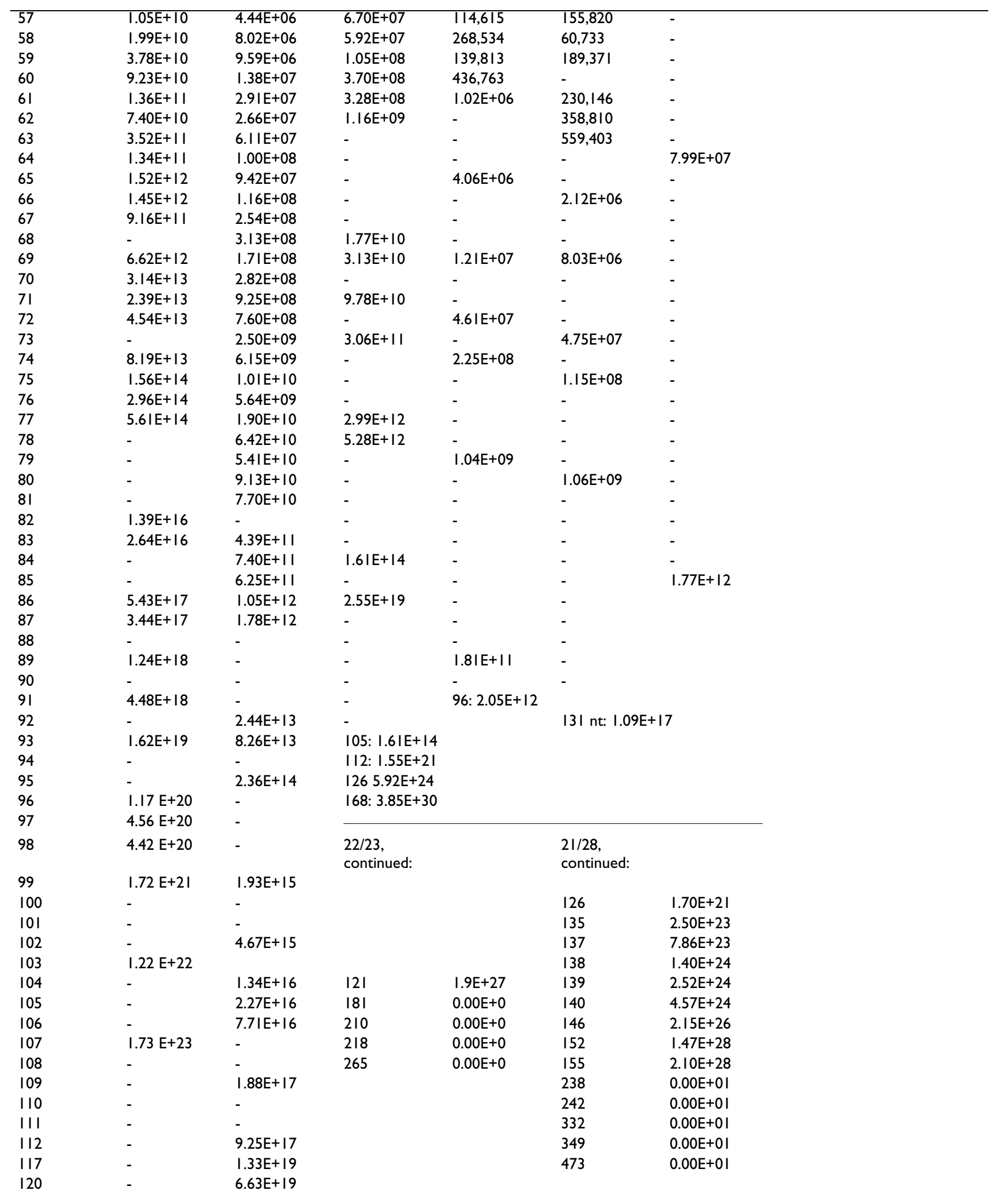


Table 5: W Tracts in Selected Chromosomes. The numbers give for each length the number of found tracts divided by the number expected tracts, eq (I). (Continued)

\begin{tabular}{lccccccc}
\hline Summary & $\begin{array}{c}\text { H. sap. 22, } \\
\text { contig 23 }\end{array}$ & $\begin{array}{c}\text { H. sap. 21, } \\
\text { contig 28 }\end{array}$ & D. mel. IIR & C. eleg. I & A. thal. II & S. cer. IV & M. jan. \\
\hline All up to: & 67 & 81 & 62 & 52 & 59 & 40 & 33 \\
Next missing & 73 & 88 & 64 & 62 & 64 & 42 \\
Longest: & 265 & 473 & 168 & 96 & 131 & 85 & 56 \\
\hline
\end{tabular}

For instance, we have seen that purines avoid being flanked by pyrimidines, and prefer to be flanked by purines. Specifically, a single A, or a single G prefer an A or a $\mathrm{G}$ base next to them. This effect is formally a first order Markov effect, but we prefer the biological viewpoint that a particular function with selective advantage, rather than an inherent neighbor effect, drives the bases together to form binary tracts. A neutral, nonfunctional driving force towards excess of purine.pyrimidine caused by different substitution mutation rates has indeed been noted [32]. The substitution rates in the direction of allpurine or all-pyrimidine tracts were however the lowest [32] and are therefore unlikely to explain the massive excesses of R.Y tracts observed.

The vast excess of long binary tracts raises two questions: Is an essential structural and/or functional role responsible for the high numbers of binary tracts in the range of species studied? And if so, has that property been conserved throughout evolution, or have convergent processes been responsible for their wide spread presence? As to the second question, the reappearance of massive $\mathrm{W}$ tracts in Drosophila can be quoted in favor of independent (convergent) evolution, while if conservation would be the answer, an early progenitor with only a binary code could be suspected. A previous suggestion of an early RNY or YRN progenote is not in line with an all purine or all pyrimidine progenote [33]. More comparative binary DNA mapping will be required to answer this question.

This leaves the question of what can the essential function be. We, and others, have proposed that a special propensity of the binary tracts to unwind and be strand separated may be responsible. Ready unwinding is certainly expected for $\mathrm{W}$ tracts, based on their established melting properties. As to R.Y tracts, Weintraub and Larsen showed, in their seminal work [34], that certain purine/pyrimidine rich sequences in the $5^{\prime}$ promoter region of the chicken beta globin gene complex are sensitive to single-strand DNA specific nucleases. Sensitivity to single-stranded specific nucleases means that these binary DNA regions have to be strand separated, at least temporarily. Since 1982,
R.Y tracts in promoters of many genes (reviewed in [35]) have been found to be attacked by single-strand specific nucleases and hence are likely to undergo a transition into a strand separated state, at least temporarily. The list of these promoters includes a number of yeast and bacterial sequences characterized as AT rich [36,37]. The singlestrand nuclease sensitive regions have been called by Umek and Kowalski DNA Unwinding Elements, or DUE's [38]. Evidence from modification by chemical reagents attacking only unpaired bases, like permanganate $[39,40]$, chloroacetaldehyde [41] and osmium tetroxide [42] support at least intermittent conversion of the attacked strands into an unwound state $[43,44]$. We have previously found that in yeast chromosomes III and XI [14] the highest binary tract concentrations are in the 5 ' promoter regions. This intriguing observation deserves a separate analysis of the promoter regions, which is in progress.

In our experimental work [17] we studied two yeast promoters that contain long oligopyrimidine tracts, namely the promoter regions of gene $c y c 1$, which has an oligopyrimidine tracts of $40 \mathrm{nt}$, and of gene ded1, with a $32 \mathrm{nt}$ pyrimidine tract (interrupted by a TATA box). These oligo Y regions, and their complementary $\mathrm{R}$ tracts, were found to be sensitive to the single-strand specific nuclease P1 when under normal cellular superhelical stress. Topological analysis was consistent with the opening of six turns of the primary helix. These findings strongly support the idea that binary tracts in critical regions can readily unwind and thus facilitate the transcription initiation process, possibly helped by single strand specific proteins. The notion that binary DNA tracts can lead to transitional strand opening can apply also to other DNA directed processes, including recombination, replication and segregation. We found evidence that a long $\mathrm{W}$ tract in the centromere yeast chromosome IV (78 nt) has a strong propensity to form an unwound structure [40]. A role in these processes can provide an explanation for the massive presence of the binary tracts in intergenic regions, far from transcriptional start sites. 
As said, the early melting of $\mathrm{W}$ tracts is a well-established fact, while for $S$ tracts the propensity to be methylated may be involved. It is somewhat harder to understand why R.Y or K.M tracts should readily unwind and form paranemic, unwound DNA structures [35] (also known as a local supercoil-stabilized structures [43]), especially when $\mathrm{G}$ or $\mathrm{C}$ rich. It is possible that the contribution of the different dinucleotides to stability [45] changes under superhelical stress and at ambient temperatures. Experiments to clarify this possibility have yet to be carried out. It should be noted that the bulk of the binary tracts observed here do not have the internal symmetries associated with paranemic structures such as DNA triplexes, cruciforms or even B-Z junctions. The DUE's are more likely to separate into single-strands and be stabilized by cellular proteins.

Are the observed binary tracts "simple" sequences in the usual sense, i.e. are the observed tracts composed of one or few nucleotides repeated many times, like oligo (C-T)? A detailed inspection of the tracts listed by the program demonstrates that for most tracts this is not the case: To get an idea, the last 15 longer tracts of contig 23, located beyond the last gene of the contig, are shown in Additional file: 7 . The list contains a few simple sequences, for instance a $17 \mathrm{nt}$ tract with $\mathrm{GA}$ repeated 8 times, $\left((\mathrm{GA})_{8} \mathrm{G}\right)$. Some longer tracts may also show simple repeats within their sequence. For example, the long $367 \mathrm{nt} \mathrm{R}$ tract has a number of GGGAGGAGAGA repeats in it (see Additional file: 7). This repeat covers however only part of the tract and the other parts are much more random. A slippage mechanism [46] would need too many "slippages" to explain this tract, or many other tracts in the lists, as generated by TRACTS. Oligo A or Oligo T tracts are partial components of quite a number of $\mathrm{R}$ tracts (as well as of $\mathrm{W}$ and $M$ tracts) and for these an additional mechanism may be operative. Nevertheless, the bulk of the binary tracts are just as random a mixture of two nucleotide bases as can be, and cannot be regarded as simple or even cryptic elements [46]. A full quantitative analysis has yet to be undertaken.

Finally, Table 6 documents another intriguing finding connected with the name of Erwin Chargaff, namely that in single strands the percentage of purines is equal to the percentage of pyrimidines. The same equality was found for $\mathrm{A}+\mathrm{C}$ bases being equal to $\mathrm{G}+\mathrm{T}$ bases, again in single strands $[47,48]$. This phenomenon has been termed "the second parity rule of Chargaff". The percentages of $A+G$ and $\mathrm{A}+\mathrm{C}$ shown in Tables 3 and 6 demonstrate that their closeness to $50 \%$ is quite convincing. I have not encountered serious departures from that rule down to the length of individual genes, in all phyla studied, including bacteria. Two explanations have been raised: One explanation is that random inversion of homopurines during evolu- tion caused this equality [49-51]. An alternative possibility is that there is a lot of potential or actual secondary structure in genomic DNA [52]. A definite explanation has yet to be provided and is beyond the scope of this paper. In conclusion, it thus seems that the analytical findings of the Late E. Chargaff will keep us busy for a while to come.

\section{Conclusions}

This paper documents one of the more significant departures of DNA from randomicity, namely that genomes exhibit an enormous excess of DNA tracts composed of only two bases. This phenomenon is conserved throughout evolution, and is therefore likely to reflect a specific DNA function. A most likely function is a propensity of these binary tracts (and possibly additional base combinations) to adopt under suitable condition an alternative, paranemic conformation. This notion is supported by a range of experimental evidence, detailed in the discussion part. We are presently examining whether a particularly high excess of the binary tracts is present in human promoters, as already found in yeast (R.Y tracts) and E. coli (W tracts), supporting a role for the binary DNA tracts in the regulation of transcription and other DNA directed processes.

\section{Methods}

Program TRACTS identifies all binary tracts in a given DNA sequence. The program was run in its original FORTRAN version $[9,15]$ on an UNIX platform. A cgi web server version, in perl, is now available [26] at url: http:// www.weizmann.ac.il/ nlcyagil/binaries refs.html. The program calculates overall binary tract frequencies (see Table 2) as well as distributions in genic sub regions exons, introns and intergenic regions. A further output of TRACTS shows the sequence entered, with each exon and intron indicated and each binary tract beyond a given length shown in color on or below the line. For more details, see [26]. A preprogram, ANEX, parses GenBank/ DDJB/EMBL annotation files (flat format) and produces a file with a one line entry for each gene which includes a short comment on the product/function of the gene. When only a single or a few genes is examined, a list of all exons and introns is produced.

In GenBank files that contain both mRNA and CDS entries, the mRNA entries were parsed. Consequently, UTR regions are mostly part of the exonic sub regions. In yeast, C. elegans and M. jannaschii, where no mRNA data are yet available, the UTR regions are necessarily counted as intergenic (intercoding, to be strict). The accession and version numbers of the genomes analyzed are shown in Table 1. In humans, two large contigs, making up most of chromosomes 21 and 22, were analyzed: The "28" contig of chr. 21 which goes from the centromere through most of the $\mathrm{q}$ arm $(28,515,322 \mathrm{nt})$ and makes up $85 \%$ of the 
Table 6: Binary tracts longer or equal to $15 \mathrm{nt}$, in 7 genomes. Ratio of found to expected tracts.

\begin{tabular}{|c|c|c|c|c|}
\hline & & R.Y & K.M & W;S \\
\hline & & \multicolumn{3}{|c|}{ H. sap. Chr. 22 Contig 23} \\
\hline & $\% A, X^{b}:$ & 50.0 & 49.9 & 52.6 \\
\hline All Regions & & 40.35 & 27.75 & 27.25 \\
\hline Exons $^{\mathrm{a}}$ & & 18.20 & 7.84 & 12.04 \\
\hline Introns & & 38.81 & 29.00 & 26.43 \\
\hline \multirow[t]{3}{*}{ Intergenic } & & 41.46 & 27.87 & 27.93 \\
\hline & & \multicolumn{3}{|c|}{ H. sap. Chr2I, Contig 28} \\
\hline & $\% A, X:$ & 50.1 & 50.2 & 0.96 \\
\hline All Regions & & 31.14 & 20.59 & 5.29 \\
\hline Exons ${ }^{\mathrm{a}}$ & & 16.48 & 7.94 & 2.14 \\
\hline Introns & & 36.31 & 24.14 & 5.24 \\
\hline \multirow[t]{3}{*}{ Intergenic } & & 30.33 & 20.06 & 5.33 \\
\hline & & \multicolumn{3}{|c|}{ D. mel. Chr. II-Right arm } \\
\hline & $\% A, X:$ & 50.0 & 50.0 & 56.6 \\
\hline All Regions & & 10.32 & 16.84 & 10.52 \\
\hline Exons $^{a}$ & & 4.32 & 7.37 & 3.40 \\
\hline Introns & & 12.89 & 21.95 & 12.08 \\
\hline \multirow[t]{3}{*}{ Intergenic } & & 12.14 & 18.96 & 13.78 \\
\hline & & \multicolumn{3}{|c|}{ C. elegans Chr. I } \\
\hline & $\% A, X:$ & 50.0 & 50.0 & 64.0 \\
\hline All Regions & & 15.70 & 9.20 & 3.05 \\
\hline Exons & & 16.41 & 8.91 & 3.18 \\
\hline Introns & & 16.89 & 8.93 & 3.11 \\
\hline \multirow[t]{3}{*}{ Intercoding } & & 15.09 & 9.38 & 2.99 \\
\hline & & \multicolumn{3}{|c|}{ A. thal. Chr. II } \\
\hline & $\% A, X:$ & 49.9 & 50.1 & 64.1 \\
\hline All Regions & & 23.82 & 3.39 & 2.65 \\
\hline Exons ${ }^{\mathrm{a}}$ & & 18.57 & 2.10 & 0.12 \\
\hline Introns & & 20.76 & 4.25 & 1.81 \\
\hline \multirow[t]{3}{*}{ Intergenic } & & 27.03 & 2.04 & 4.05 \\
\hline & & \multicolumn{3}{|c|}{ S. cer. Chr. IV } \\
\hline & $\% A, X:$ & 50.1 & 50.1 & 62.1 \\
\hline All Regions & & 15.32 & 5.52 & 1.60 \\
\hline Exons & & 9.16 & 3.64 & 0.42 \\
\hline Introns & & 7.76 & 0.00 & 2.33 \\
\hline \multirow[t]{3}{*}{ Intercoding } & & 33.25 & 11.07 & 4.96 \\
\hline & & \multicolumn{3}{|c|}{ M. jan. Chromosome } \\
\hline & $\% A, X:$ & 50.3 & 50.0 & 68.6 \\
\hline All Regions & & 15.73 & 3.21 & 1.53 \\
\hline Exons & & 17.39 & 3.09 & 0.93 \\
\hline Introns & & 0.00 & 0.00 & 0.00 \\
\hline Intercoding & & 4.7 & 4.04 & 5.60 \\
\hline
\end{tabular}

$a-$ Including identified $3^{\prime}$ and $5^{\prime}$ UTR regions. $b-A, X$ is: A,G for R.Y; A,C for K.M and A,T for W;S.

sequenced chromosome; and the "23" contig of chr. 22 $(22,998,450 \mathrm{nt})$, which makes up $66.6 \%$ of the sequenced chromosome.

\section{Expected binary tract frequencies}

Frequencies of binary tracts expected in random DNA are calculated as following: $\mathrm{N}(\mathrm{l})$ gives the number of tracts of length l expected in random DNA of length $\mathrm{L}$ and of fractional base composition $\mathrm{p}$ by: 
Table 7: Masked and non-masked frequencies of long R.Y tracts. In contig 3.45 of human chromosome 2 I

\begin{tabular}{ccccccc}
\hline & \multicolumn{3}{c}{ Masked sequence $(2,125,818 \mathrm{nt})$} & \multicolumn{3}{c}{ Full sequence $(3,450,347 \mathrm{nt})$} \\
\cline { 2 - 7 } & f/e ratio GE I5 & UP to $(\mathrm{nt})$ & Longest $(\mathrm{nt})$ & f/e ratio GE I5 & UP to (nt) & Longest (nt) \\
\hline R.Y & 22.6 & 44 & 171 & 28.0 & 44 & 175 \\
K.M & 18.8 & 46 & 121 & 23.7 & 50 & 121 \\
W;S & 6.03 & 36 & 134 & 21.4 & 42 & 134 \\
\hline
\end{tabular}

$$
N(l)=L\left(p^{l} \mathbf{x} q^{2}+q^{l} \times p^{2}\right)
$$

where $p, q$ are the fractions of the participating base pairs, $\mathrm{p}+\mathrm{q}=1$ ( $p$ is e.g. the fraction of $\mathrm{A}+\mathrm{G})$. To calculate expected values for only one member of a pair, only one member of the above sum is to be used. The number of bases expected in tracts of length $n(l)$ is simply:

$n(l)=l \times N(l)$.

The expected number of tracts equal or greater (GE) than a given length $l, N(\geq l)$, can be shown to be [9]:

$N(\geq l)=\mathrm{L}\left(p \times q^{l}+q \times p^{l}\right)$

The expected number of bases in these tracts, $\mathrm{n}(\geq \mathrm{l})$, is:

$n(\geq l)=\mathrm{L}\left\{(p+q l) p^{l}+(q+p l) q^{l}\right\}$.

The validity of these expressions was tested by generating random DNA sequences and running them by TRACTS. For this paper, five $1 \mathrm{Mb}$ random sequences with exactly $25 \%$ of each nucleotide base were generated and run for each binary composition, so that standard deviations could be calculated and are listed in Additional file: 4 . The percentage of $\mathrm{W}$ and $\mathrm{S}$ bases in the analyzed chromosomes is not $50 \%$, but a control run with $62.5 \%$ AT was previously run for $\mathrm{H}$. influenzae, giving the same picture [15].

\section{Abbreviations}

chr. - chromosome

GE - Greater or Equal (longer or equal)

\section{Additional material}

\section{Additional File 1}

Table 1. Binary tract frequencies in contig 28 of human chromosome 22 Click here for file

[http://www.biomedcentral.com/content/supplementary/1471-

2164-5-19-S1.txt]

\section{Additional File 2}

Table 2. Binary tract frequencies in Drosophila chromosome R2 Click here for file

[http://www.biomedcentral.com/content/supplementary/14712164-5-19-S2.txt]

\section{Additional File 3}

Table 3. Binary tract frequencies of yeast chromosome IV Click here for file

[http://www.biomedcentral.com/content/supplementary/1471-

2164-5-19-S3.txt]

\section{Additional File 4}

Table 4. Five random sequences, $1 \mathrm{Mb}$ each.

Click here for file

[http://www.biomedcentral.com/content/supplementary/14712164-5-19-S4.txt]

\section{Additional File 5}

Table 5. Frequencies of $S$ tracts in seven sequenced chromosomes. Click here for file

[http://www.biomedcentral.com/content/supplementary/14712164-5-19-S5.xls]

\section{Additional File 6}

Table 6. Masked regions in contig 3.45 of human chromosome 21. Click here for file

[http://www.biomedcentral.com/content/supplementary/14712164-5-19-S6.txt]

\section{Additional File 7}

Table 7. All R.Y tracts longer than $10 \mathrm{nt}$, beyond position 22,944,530 of contig 23.

Click here for file

[http://www.biomedcentral.com/content/supplementary/1471-

2164-5-19-S7.txt]

\section{Additional File 8}

Table 8. Contig 28 in windows of $2 \mathrm{Mb}$ - fle ratio GE 13 . Click here for file

[http://www.biomedcentral.com/content/supplementary/14712164-5-19-S8.xls]

\section{Acknowledgements}

Dedicated to Erwin Chargaff (1905-2002), a pioneer. I am indebted to Dr. Jaime Prilusky for many helpful advices and to Dr. Shifra Ben-Dor for thoughtful comments to the manuscript. The help of many other members of the Biological Computing Unit of this Institute is gratefully acknowledged. 


\section{References}

I. Tamm C, Shapiro HS, Lipshitz R, Chargaff E: Distribution density of nucleotides within a deoxyribonucleic acid chain.J Biol Chem 1953, 203:673-688.

2. Spencer $\mathrm{H}$, Chargaff E: Studies on nucleotide arrangement in deoxyribonucleic acids, VI. Pyrimidine clusters: Frequency and distribution in several species of the AT type. Bioch Bioph Acta 1963, 68:9-27.

3. Petersen GB: The distribution of nucleotides in deoxyribonucleic acid. Biochem J 1963, 87:495-500.

4. Spencer $\mathrm{JH}$, Chargaff E: Pyrimidine nucleotide sequences in deoxyribonucleic acids. Bioch Bioph Acta I96 I, 5 I:209-2 I I.

5. Shapiro HS, Chargaff E: Studies on nucleotide arrangement in deoxyribonucleic acids VI. Direct estimation of pyrimidine nucleotide runs. Bioch Bioph Acta 1963, 76: I-8.

6. Szybalski W, Kubinski H, Sheldrick P: Pyrimidine clusters on the transcribing strands of DNA and their possible role in the initiation of RNA synthesis. Cold Spring Harbor Symp Quant Biol 1966 3 I:I23-127.

7. Birnboim HC, Sederoff RR, Paterson MC: Distribution of R.Y segments in DNA from various organisms. Europ J Biochem 1979 98:301-307.

8. Case ST, Baker R: Detection of long eukaryote-specific pyrimidine runs in repetitive DNA sequences and their relation to single-stranded regions in DNA isolated from sea urchin embryos. J Mol Biol 1975, 98:69-92.

9. Bucher P, Yagil G: Occurrence of oligopurine.oligopyrimidine tracts in eukaryotic and prokaryotic genes. DNA Sequence |99|, I:27-43.

10. Behe MJ: An overabundance of long oligopurine tracts occurs in the genome of simple and complex eukaryotes. Nucleic Acids Res 1995, 23:689-695.

II. Karlin S, Ghandour G: The use of multiple alphabets in kappagene immunoglobulin DNA sequence comparisons. EMBO J 1985, 4:1217-1223.

12. Antequera F, Bird A: CpG islands as genomic footprints of promoters that are associated with replication origins. Current Biol 1999, 9:R66I-R667.

13. Yagil G: The frequency of two-base tracts in eukaryotic genomes. J Mol Evol 1993, 37: I23-130.

14. Yagil G: The frequency of oligopurine.oligopyrimidine and of other two-base tracts in yeast chromosome III. Yeast 1994, 10:603-611.

15. Shomer B, Yagil G: Long $\mathbf{W}$ tracts are over-represented in the E. coli and $\boldsymbol{H}$. Influenzae genomes. Nucl Acids Res 1999, 27:449|-4480.

16. Raghavan S, Haniharan R, Brahmachari SK: Polypurine.polypyrimidine sequences in complete bacterial genomes: Preference for polypurines in protein-coding regions. Gene 2000 242:275-283.

17. Yagil G, Shimron F, Tal M: DNA unwinding in the CYCI and DEDI yeast promoters. Gene 1998, 225:152-163.

18. Hattori M, Fujiyama A, Taylor TD, Watanabe H, Yada T, Park HS, Toyoda A, Ishii K, Totoki Y, Choi DK et al.: The DNA sequence of human chromosome 2 I. Nature 2000, 405:3 I I-3 I9.

19. Dunham I, Hunt AR, Collins JE, Bruskiewich R, Beare DM, Clamp M, Smink LJ, Ainscough R, Almeida JP, Babbage A et al.: The DNA sequence of human chromosome 22. Nature 1999, 402:489-495.

20. Adams MD, Celniker SE, Holt RA, Evans CA, Gocayne JD, Amanatides PG, Scherer SE, Li PW, Hoskins RA, Galle RF et al:: The genome sequence of Drosophila melanogaster. Science 2000, 287:2185-2195.

21. C. elegans Sequencing Consortium: Genome sequence of the nematode $C$. elegans: A platform for investigating biology. Science 1998, 282:2012-2018.

22. Lin XY, Kaul S, Rounsley S, Shea TP, Benito MI, Town CD, Fuji CY Mason T, Bowman CL, Barnstead $M$ et al.: Sequence and analysis of chromosome 2 of the plant Arabidopsis thaliana. Nature 1999, 402:761-768.

23. Jacq $C$, and I 38 colleagues: The nucleotide sequence of $S$. cerevisiae chromosome IV. Nature 1997:75-78.

24. Bult CJ, White O, Olsen GJ, Zhou L, Fleischmann RD, Sutton GG, Blake JA, FitzGerald LM, Clayton RA, Gocayne JD et al.: Complete genome sequence of the methanogenic archeon, Methanococcus jannaschii. Science 1996, 273:1058-1073.
25. Davuluuri RV, Grosse IV, Zhang MQ: Computational identification of promoters and first exons in the human genome. Nature Genetics 200I, 29:4I2-4I7.

26. Gal M, Katz T, Ovadia A, Yagil G: TRACTS: A program to map oligopurine.oligopyrimidine and other binary DNA tracts. Nucl Acids Res 2003, 3 I:3679-368I

27. Zubiaga AM, Belasco JG, Greenberger ME: The nonamer UUAU. UUAUU is the key AU-rich sequence motif that mediates mRNA degradation. Mol Cell Biol 1995, I 5:2219-2230.

28. Chargaff E: Essays in Nucleic Acids Amsterdam Elsevier 1963: I 26ff- I 46ff.

29. Shapiro HS, Rudner R, Miura K-I, Chargaff E: Inferences from the distribution of pyrimidine isostichs in deoxynucleic acids. Nature 1965, 205: 1068-70.

30. Yagil G: Binary DNA tracts can serve as DNA unwinding centers. I Biomolecular Struct Dyn 200 I, I 8:9 | I-9| I.

31. Gentles AJ, Karlin S: Genome-scale compositional comparisons in eukaryotes. Genome Res 200 I, I I:540-546.

32. Hess ST, Blake JD, Blake RD: Wide variations in neighbordependent substitution rates. J Mol Biol 1994, 236: I022-1033.

33. Eigen $M$, Osswatich-Winkler R: Transfer-RNA, an early gene? Naturwissenschaften 1981, 68:282-292.

34. Larsen A, Weintraub $\mathrm{H}$ : An altered DNA conformation detected by $\mathrm{SI}$ nuclease occurs at specific regions in active chick globin chromatin. Cell 1982, 29:609-6I6.

35. Yagil G: Paranemic structures of DNA and their role in DNA unwinding. Crit Revs Biochem Mol Biol I99I, 26:475-559.

36. Kowalski D, Eddy MJ: The DNA unwinding element: A novel, cis acting component that facilitates the opening of the $E$. Coli replication origin. EMBO J 1989, 8:4335-4339.

37. Bramhill $D$, Kornberg $A$ : $A$ model for initiation at origins of DNA replication. Cell I988, 54:915-917.

38. Umek RM, Eddy MJ, Kowalski D: DNA sequences required for unwinding prokaryotic and eukaryotic replication origins. Cancer Cells 1988, 6:473-478.

39. Borowiec JA, Hurwitz J: Localized melting and structural changes in the SV40 origin of replication induced by T-antigen. EMBO J 1988, 7:3149-3158.

40. Tal M, Shimron F, Yagil G: Unwound regions in yeast centromere DNA. J Mol Biol I994, 243:I79-I89.

4I. Kohwi Y, Kohwi-Shigematsu T: Structural polymorphism of homopurine-homopyrimidine sequences at neutral pH. J Mol Biol I993, 23 I: I090-II0I.

42. Palecek E, Robert-Nicoud M, Jovin T: Local opening of the DNA double helix in eukaryotic cells, detected by osmium probe and adduct-specific immunofluorescence. J Cell Sci 1993 104:653-66I.

43. Palecek E: Local supercoil-stabilized DNA structures. Crit Rev Biochem Mol Biol |99|, 26: I5I-226.

44. Benham C, Kohwi-Shigematsu T, Bode J: Stress-induced duplex DNA destabilization in scaffold/matrix attachment regions. Mol Biol 1997, 274: I8I-196.

45. SantaLucia J: A unified view of polymer, dumbbell, and oligonucleotides DNA nearest-neighbor thermodynamics. Proc Nat Acad Soc (USA) 1998, 95: |460- | 465.

46. Tautz $D$, Trick $M$, Dover GA: Cryptic simplicity in DNA is a major source of genetic variation. Nature 1986, 322:652-656.

47. Elson D, Chargaff $\mathrm{E}$ : Evidence for common regularities in the comparison of pentose nucleic acids. Bioch Bioph Acta 1955, I 7:362-376

48. Rudner R, Karkas JD, Chargaff E: Separation of B. subtilis DNA into complementary strands III. Direct analysis. Proc Natl Acad Soc (USA) 1968, 63:921-922.

49. Baisnee P-F, Hampson S, Baldi P: Why are complementary DNA strands symmetric? Bioinformatics 2002, I 8: |02|-1033.

50. Lobry JR: Properties of a general model of DNA evolution under no-strand-bias conditions. J Mol Evol 1995, 40:326-330.

5I. Sueoka N: Intrastrand parity rules of DNA base composition and usage biases of of synonymous codons. J Mol Evol 1995 , 40:318-325

52. Bell SJ, Forsdyke DR: Deviations from Chargaff's second parity rule correlate with direction of transcription. J Theor Biol 1999 , 197:63-76. 